\title{
Overview of Materials Qualification Needs for Metal Additive Manufacturing
}

\author{
MOHSEN SEIFI $\odot,{ }^{1,5}$ AYMAN SALEM, ${ }^{2}$ JACK BEUTH, ${ }^{3}$ \\ OLA HARRYSSON, ${ }^{4}$ and JOHN J. LEWANDOWSKI ${ }^{1}$
}

1.-Department of Materials Science and Engineering, Case Western Reserve University, Cleveland, USA. 2.-Materials Resources LLC, Dayton, OH, USA. 3.-Department of Mechanical Engineering, Carnegie Mellon University, Pittsburgh, USA. 4.-Department of Industrial and Systems Engineering, North Carolina State University, Raleigh, USA. 5.-e-mail: mohsen.seifi case.edu

This overview highlights some of the key aspects regarding materials qualification needs across the additive manufacturing (AM) spectrum. AM technology has experienced considerable publicity and growth in the past few years with many successful insertions for non-mission-critical applications. However, to meet the full potential that AM has to offer, especially for flightcritical components (e.g., rotating parts, fracture-critical parts, etc.), qualification and certification efforts are necessary. While development of qualification standards will address some of these needs, this overview outlines some of the other key areas that will need to be considered in the qualification path, including various process-, microstructure-, and fracture-modeling activities in addition to integrating these with lifing activities targeting specific components. Ongoing work in the Advanced Manufacturing and Mechanical Reliability Center at Case Western Reserve University is focusing on fracture and fatigue testing to rapidly assess critical mechanical properties of some titanium alloys before and after post-processing, in addition to conducting nondestructive testing/evaluation using micro-computerized tomography at General Electric. Process mapping studies are being conducted at Carnegie Mellon University while large area microstructure characterization and informatics (EBSD and BSE) analyses are being conducted at Materials Resources LLC to enable future integration of these efforts via an Integrated Computational Materials Engineering approach to AM. Possible future pathways for materials qualification are provided.

\section{INTRODUCTION}

The field of additive manufacturing $(\mathrm{AM})^{1}$ has experienced significant growth over the past 25 years in areas ranging from the number of machines sold to the number of parts produced, with equivalent increases in research and development activities in the form of publications and patents. $^{2}$ According to the most recent Wohlers report, ${ }^{2}$ the sale of $\mathrm{AM}$ products and services could reach US $\$ 3.7$ billion worldwide by 2015 , and exceed US $\$ 6.5$ billion by 2019. With its acquisition of Phenix Systems, 3D Systems became the only U.S. producer of a powder bed direct metal AM system. In contrast, the U.S. is the leading user of AM systems ${ }^{2}$ with $38 \%$ of all worldwide AM equipment installations, while Fig. 1 illustrates the market share amongst the various powder bed AM systems. In order to fully realize the potential of AM, considerable research and development efforts are required, particularly for complex metal components (e.g., aerospace, biomedical, and automotive parts) in fracture-critical applications. While the National Science Foundation (NSF) has awarded almost 600 grants since the 1970s for fundamental research on AM technologies, ${ }^{3}$ more recent support that has focused on higher Technology Readiness Level (TRL) projects includes that provided to Industry/University/Government Lab teams through the Pilot Institute for Additive Manufacturing, initially known as 


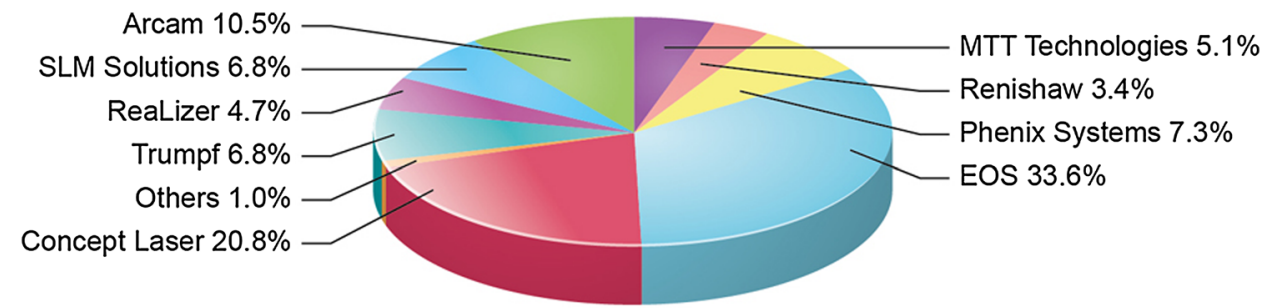

Fig. 1. Market share among metal powder bed fusion AM systems, (Trumpf uses directed energy deposition method). Adapted from Ref. 2.

the National Additive Manufacturing Innovation Institute (NAMII) and now known as America Makes.

While AM is also increasingly being explored for the development of new products, variation in the part quality and mechanical properties due to inadequate dimensional tolerance, presence of defects, surface roughness, and residual stress can limit its use in high-value or mission-critical applications. Various roadmap efforts have been conducted for $\mathrm{AM}^{4,5}$ as well as updates regarding the status of research needs for qualification and certification. 6 ,7 The recent review of the metal AM process by Frazier ${ }^{8}$ highlights the drastic variability in the various stages in process that produces multiple challenges for the development of qualification standards. Other recent reviews ${ }^{9,10}$ dealing with qualification/certification highlight additional needs.

The current overview will focus on the direct metal laser melting (DMLM; e.g., EOS) and electron beam melting (EBM; e.g., Arcam) powder bed processes since they are viewed as the most successful direct metal AM processes in the automated building of high-quality shapes. Our objective is to summarize ongoing work and issues as well as provide an update to the previous work ${ }^{11}$ that has demonstrated location- and orientation-dependent properties on $\mathrm{Ti}-6 \mathrm{Al}-4 \mathrm{~V}$ that are affected by microstructure variations and process-induced defects in as-deposited material. Although the asdeposited materials reported in that published work $^{11}$ exhibited some properties (i.e. fatigue crack growth, fracture toughness) approaching those of some cast/wrought materials, industrial input from both the aerospace and biomedical communities indicate the desire to use as-deposited materials in various applications where high cycle fatigue (HCF) properties are also critical. To produce functional orientation-dependent properties (e.g., HCF, toughness) required by both industries, the source(s) of process-induced defects and microstructure spatial heterogeneities must first be understood and then manipulated by control of the AM process(es). This will facilitate minimization and/or elimination of various costly post-processing techniques (e.g., heat treatment, hot isostatic pressing, etc.). The alternative is using energy-intensive and costly processes to achieve the qualification of each part, which is practiced widely today in the industry for AMprocessed metallic components.
This overview proposes the use of an Integrated Computational Materials Engineering (ICME)based platform (MiCloud.AM) (Fig. 2), while providing preliminary results to develop an understanding of the microstructure (i.e. morphology and crystallography), defects, and source(s) of defect generation. These are all influenced by process control while linkages between those variables and melt pool geometry are required to eliminate/minimize such defects and produce desired properties. This could be accomplished by utilizing a verified platform for rapid qualification of powder bed direct metal AM processes.

\section{GLOBAL ACTIVITIES, SPECIAL JOURNAL ISSUES ON AM}

To reflect the anticipated impact of a successful qualification methodology for AM parts, Fig. 3 illustrates the various international $R \& D$ activities at universities, national laboratories and research institutes as part of an ongoing review, ${ }^{12}$ while specific references for various European programs $^{13,14}$ and projects ${ }^{15-23}$ are also provided. The urgent need for a widely used qualification process is reflected by the rapidly expanding AM R\&D as illustrated in Table I which summarizes a number of technical journals that have dedicated at least one journal issue to the topic of AM.

\section{INDUSTRIAL EXAMPLES OF EVOLVING AND POTENTIAL AM APPLICATIONS}

In addition to the R\&D work mentioned above, there are many active investments by various industries for utilization of AM parts to capitalize on the value-added properties provided by AM as shown in Fig. 4, which highlights some industrial examples for AM parts. In particular, General Electric (GE) has received Federal Aviation Administration (FAA) certification for fuel nozzle implementation in the GE LEAP engine, and GE Aviation will produce more than 100,000 3D-printed parts via laser-based powder bed AM by the close of this decade. In this case, AM reduced the total part count and replaced more complex brazing of multiple components to create a lighter, simpler, and more durable product. Other components are also being considered for potential replacement such as brackets. While fracture-critical components are longer-term goals, some aerospace companies have 


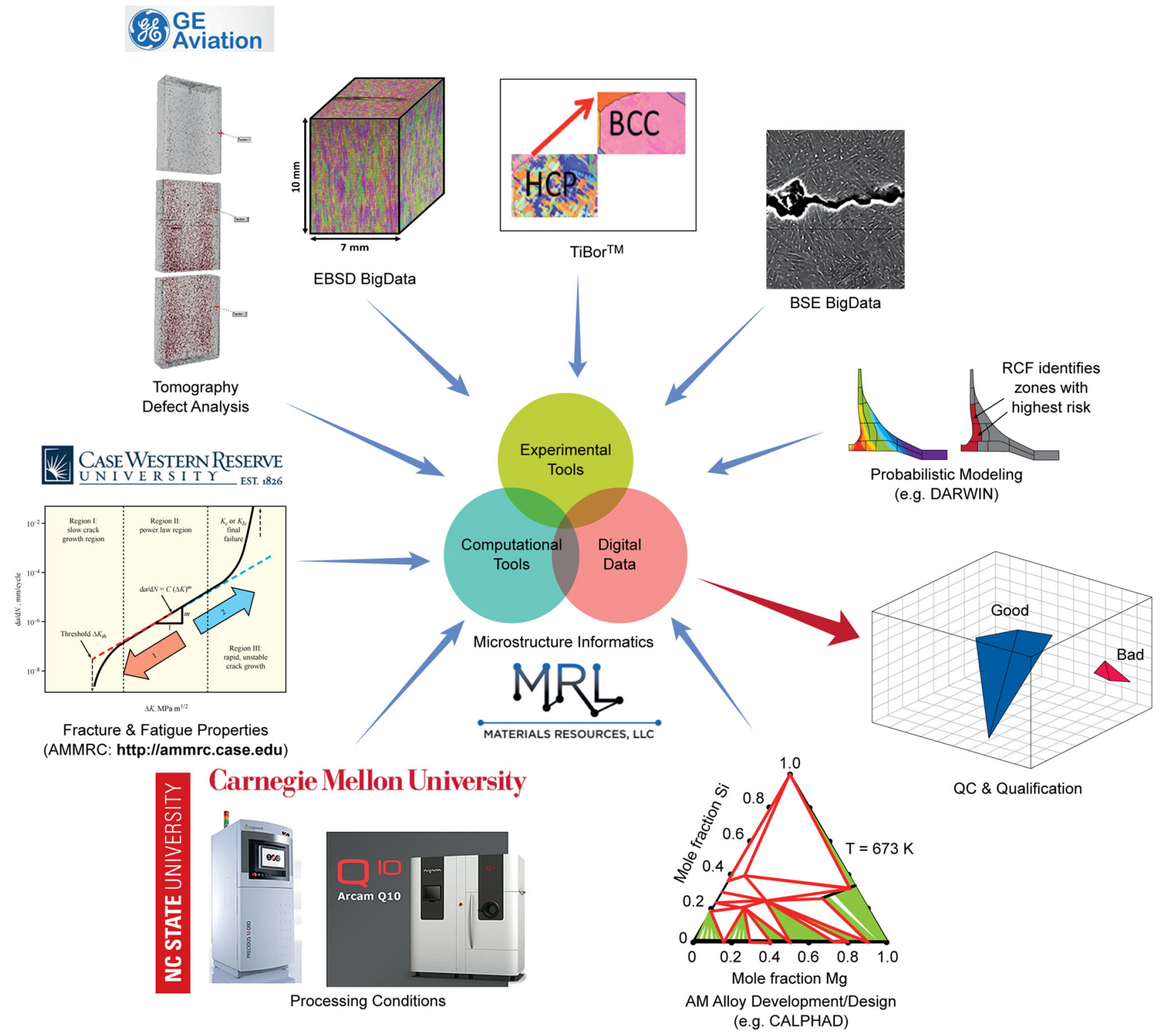

Fig. 2. MiCloud.AM ${ }^{\mathrm{TM}}$ : An integrated multi-scale ICME approach for qualification of metal additive manufacturing using Microstructure informatics Cloud computing (www.MiCloud.AM).

begun insertion into non-civilian aircraft. NASA is also considering $\mathrm{AM}$ of rocket engine components for space propulsion. ${ }^{24}$ Other non-aerospace examples include biomedical components, where the lack of standards can delay FDA approval and implementation. One FDA-approved component provided in Fig. 4 illustrates an acetabular cup for hip implants that is made by EBM.

\section{NEED FOR MULTI-SCALE INTEGRATED COMPUTATIONAL MATERIALS ENGINEERING (ICME) APPROACH}

While AM processing of a part can be conducted all within one company (from $\mathrm{CAD}$ to the final product), qualification of such a part for use in civilian or military applications can require the collection of a large amount of labor-intensive processing-, microstructure-, and property-based information. In many cases, these must be obtained from many different organizations that must then make the information available to pave the path for eventual qualification and certification. However, there are many potential intellectual property hurdles in both the generation and analysis of such data. One approach that can provide the necessary infrastructure to accelerate qualification and certification involves ICME, ${ }^{25,26}$ as outlined below and captured in Fig. 2. In the following sections, the individual components highlighted in Fig. 2 will be covered, followed by a discussion indicating the need to integrate such efforts via an ICME approach. 


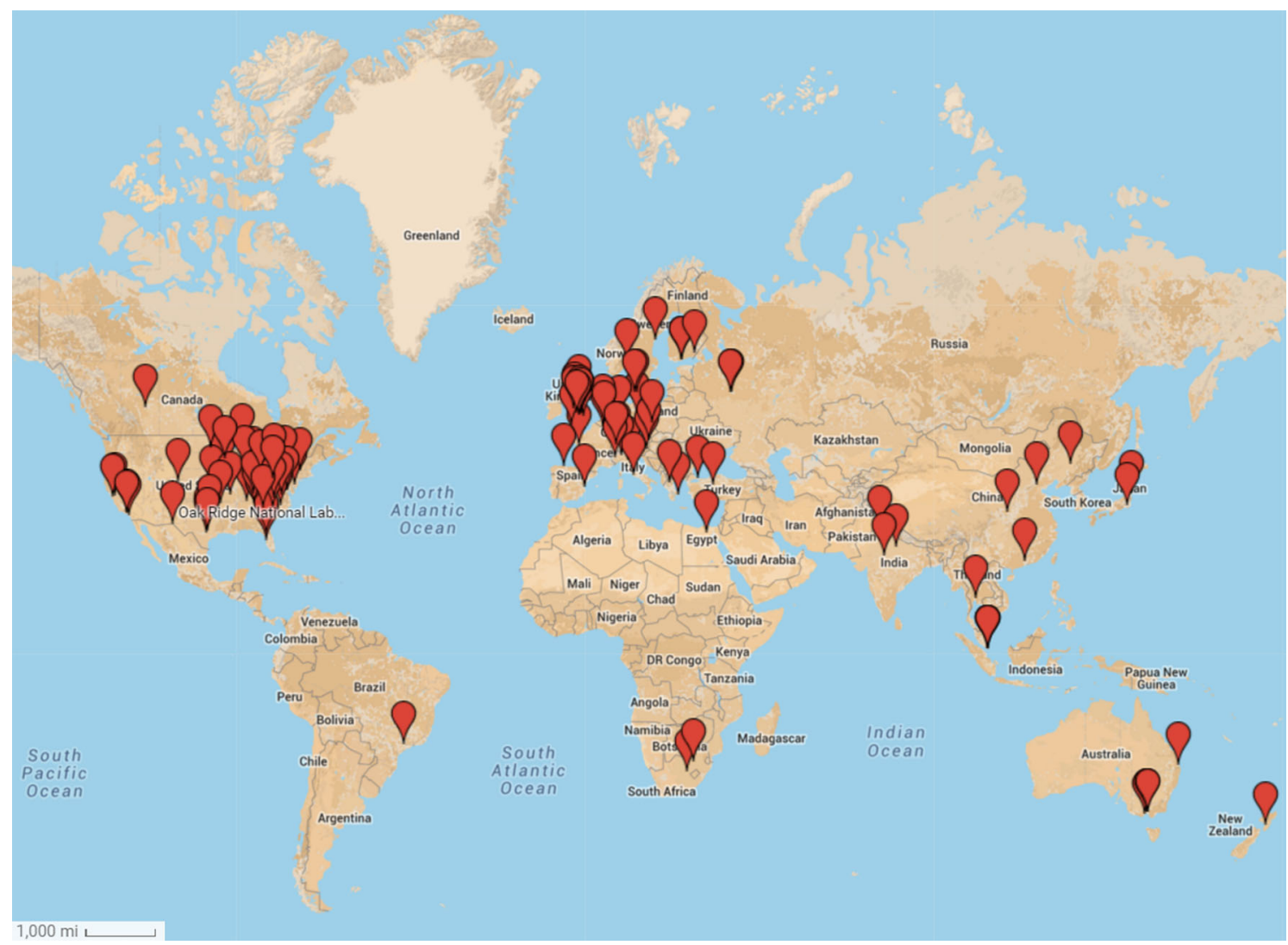

Fig. 3. Global activities on additive manufacturing across the world. Online version can be viewed at: https://goo.gl/Xp27nA (Made with Google Maps).

\section{Table I. List of journals special issues on additive manufacturing}

\section{Journal name}

Journal of Materials Research (JMR)

Journal of Manufacturing Science and Engineering (JMSE)

NIST Journal of Research

JOM

Materials Science and Technology (MST)

Materials Technology

Surface Topography: Metrology and Properties

JOM

Annual Review of Materials Research

International Journal of Fatigue

\section{Date of publication}

September 2014

October 2014

October 2014

March 2015

June 2015

End of 2015

Early 2016

March 2016

Mid 2016

October 2016

\section{AM ALLOYS, PROCESSES, AND EQUIPMENT}

The range of metals available for use in AM continues to grow as new technologies and applications emerge. Currently, the most common metallic materials are steels (tool steel and stainless), pure titanium and titanium alloys, aluminum casting alloys, nickel-based superalloys, cobalt-chromium alloys, gold, and silver. ${ }^{8}$ To utilize the full potential of AM, alloy development specifically for AM processing will require further attention. Although preliminary work on new AM materials is underway, ${ }^{27}$ a number of challenges remain including contamination issues, chemistry control during the melting process and solidification cracking, amongst others. Resulting AM parts must meet desired specifications for chemistry, surface roughness, damage tolerance, fatigue, strength, and other properties that may be sensitively affected by subtle changes to the chemistry and/or resulting microstructure and defect population. Currently, such understanding is not widely available due, in part, to a lack of detailed understanding of the processing-structure-property relationships, insufficient testing, lack of shared knowledge and 


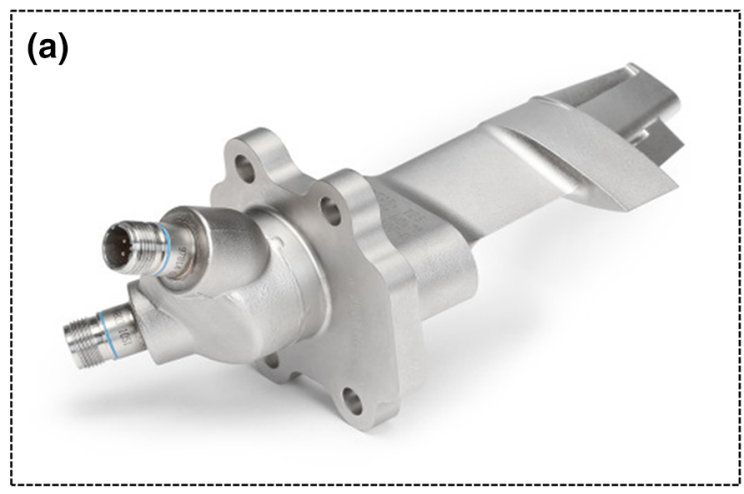

(b)
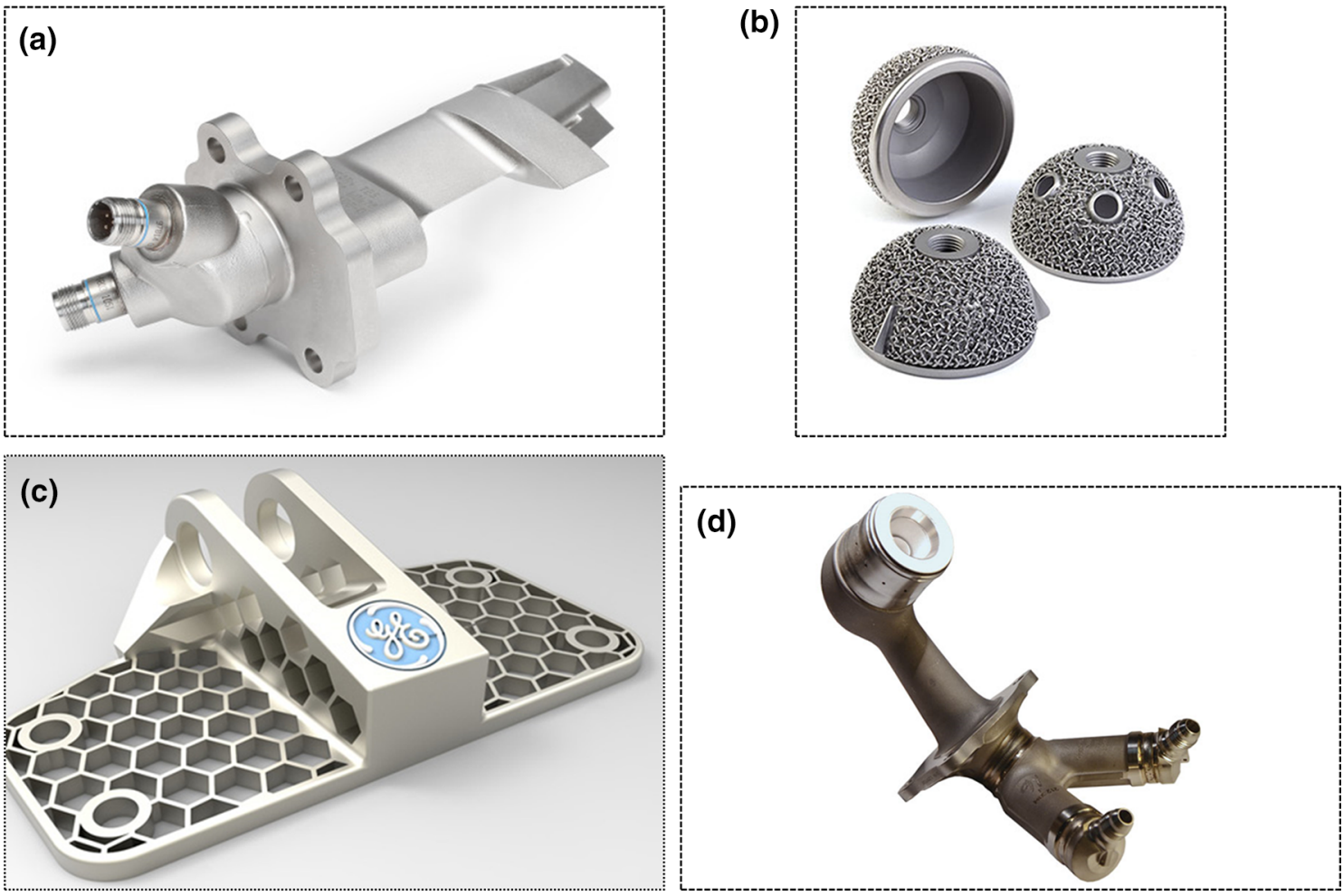

Fig. 4. Examples of parts/components made by Powder Bed Fusion AM technologies. (a) Inlet temperature sensor housing for jet turbine engine, roughly $7.5 \mathrm{~mm}$ tall; (b) Ti-6Al-4V acetabular cup produced by electron beam melting, EBM (i.e. Arcam); (c) Bracket produced via laserbased powder bed (i.e. EOS); (d) GE LEAP engine Co-Cr fuel nozzle produced via direct metal laser melting, DMLM (i.e. EOS).

materials test results across the AM community, and lack of standardized test methods for AM materials. $^{12}$

The selection of an AM material is highly dependent on the AM process that will utilize the material. Some of the most common AM processes employed for metallic materials are powder bed fusion (PBF), directed energy deposition (DED) and wire-fed AM. ${ }^{8}$ DED potentially has the capability to build parts with gradient materials (combination of two or more powders). Other metal-based processes in use, but not as common, include material jetting and ultrasonic bonding. Most AM systems melt the metal materials and produce parts with close to $100 \%$ density, with some baseline properties (e.g., tensile strength) that can match or exceed those of a cast part. ${ }^{8}$

While much progress has been made in the development of AM processes and equipment, some significant challenges remain for more widespread implementation. Improving product quality with respect to surface roughness and/or residual stresses, increasing the efficiency of production, gaining the ability to rapidly produce larger and more diverse parts, and lowering production costs are a few of the important challenges that are directly impacted by processing techniques. In addition, one of the biggest challenges relates to barriers associated with accessing and/or sharing information on the details of various AM machine setup parameters that prevents users from overriding machine-preset processing conditions, thereby preventing optimization of these conditions. Unfortunately, in many cases, overcoming these barriers requires approaches that are unique to the type of processes, equipment, and materials employed.

\section{PROCESS CONTROL AND PROCESS MAPPING}

\section{Feed Stock, Variables (Power, Velocity, Hatching, etc.), Scan Strategies, Build Orientation}

Determining the properties of the powder used for metal-based AM, as well as the properties of the solidified metal part, is a necessary condition for the industry to be able to confidently select the powders and produce consistent parts with known and predictable properties. A number of projects sponsored by America Makes ${ }^{28,29}$ are addressing the use/ reuse of powder as well as powder flow characteristics. The project involving Carnegie Mellon University (CMU), North Carolina State University (NCSU), and a large number of industry and government laboratory collaborators ${ }^{29}$ is seeking to broaden the range of powders useable in laser and electron beam powder bed processes to allow machine users to balance constraints on cost and 
(a)

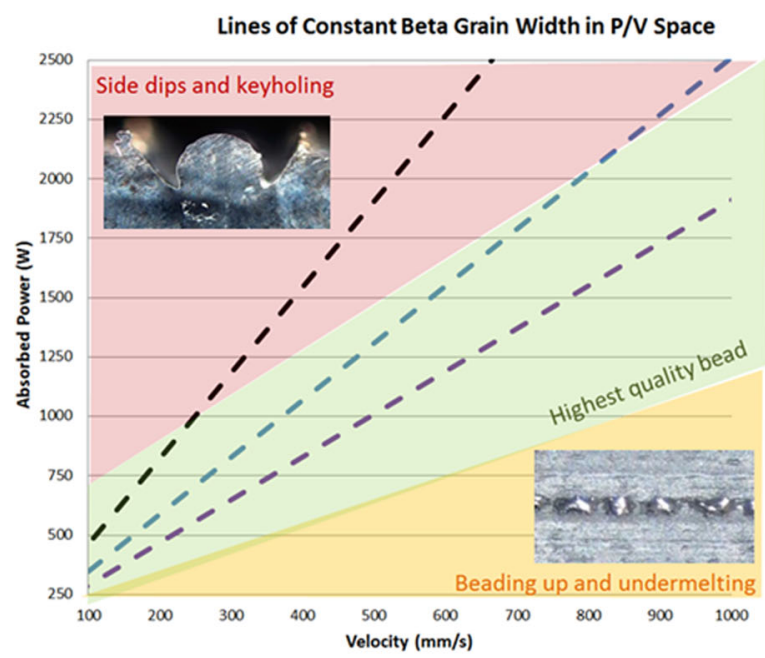

(b)

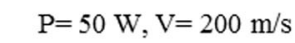

Avg. beta grain width

Black - $180 \mu \mathrm{m}$

Blue $-155 \mu \mathrm{m}$

Purple $-127 \mu \mathrm{m}$

$\mathrm{P}=195 \mathrm{~W}, \mathrm{~V}=1200 \mathrm{~m} / \mathrm{s}$
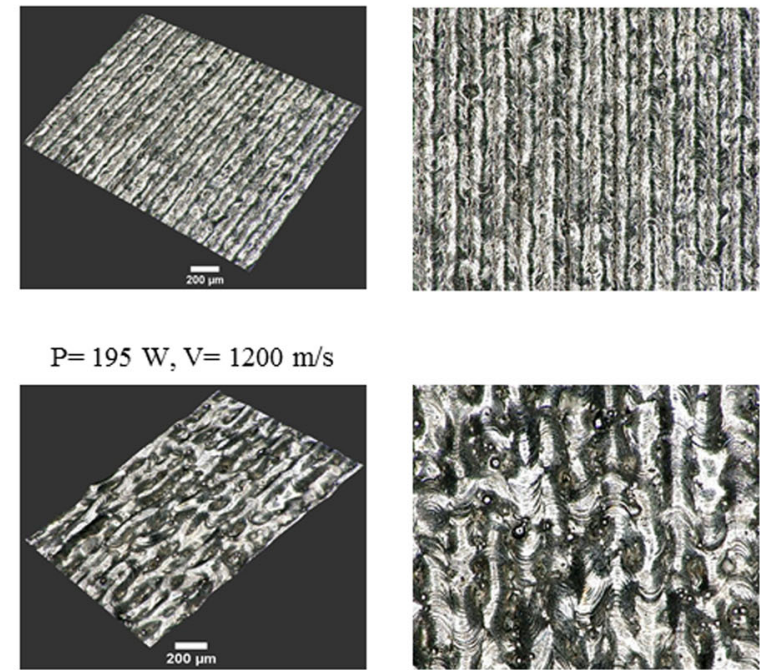

Fig. 5. (a) P-V map for electron beam processed Ti-6Al-4V showing regimes of good quality beads as well as size of beta grains. ${ }^{35}$ (b) Inset shows different scales of surface roughness of multi-layer beads produced via laser-based techniques at different $\mathrm{P}-\mathrm{V}$ combinations.

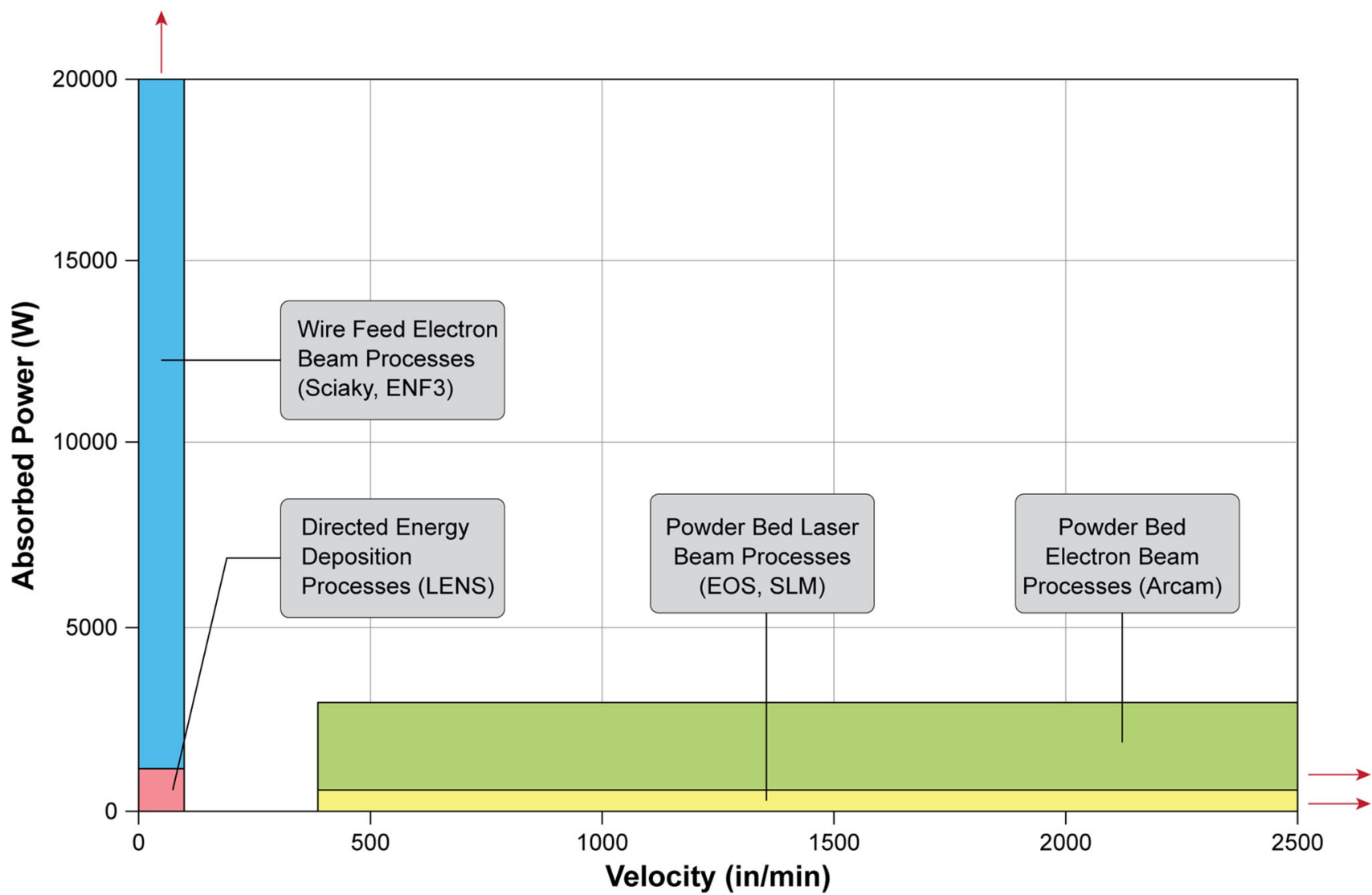

Fig. 6. Regimes of $P$ and $V$ in typical $A M$ processes.

part precision through their choice of powder systems. That project has recently demonstrated the successful use of two nonstandard Ti-6Al-4V powder systems in the Arcam machine through process variable changes.
Ongoing work at CMU/Wright State University (WSU) as part of the existing project on Rapid Qualification Methods (America Makes contract No. FA8650-12-2-7230 and Project No. 4009) led by Case Western Reserve University (CWRU) and CMU is 


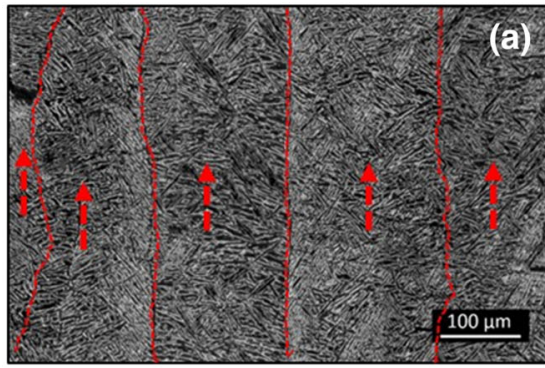

Bulk Raster

Average $\beta$ width $=91 \mu \mathrm{m}$

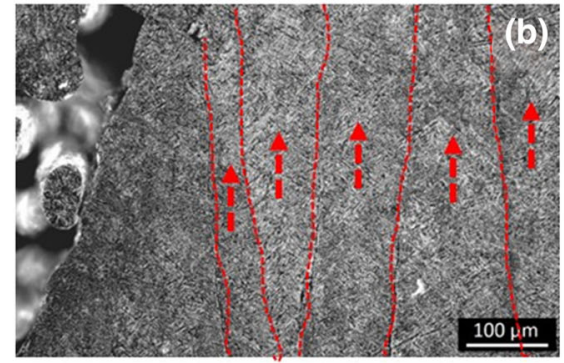

Bulk Raster

Average $\beta$ width $=177 \mu \mathrm{m}$

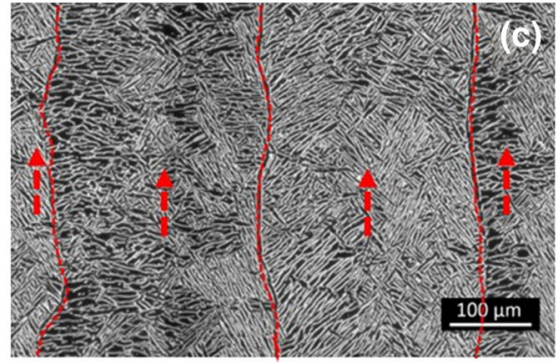

Bulk Raster

Average $\beta$ width $=277 \mu \mathrm{m}$

Fig. 7. Feedforward control of Ti-6Al-4V solidification microstructure in the Arcam process, varying beta grain width over a factor of 3.

directly developing Process Mapping strategies ${ }^{30-35}$ where beam power and velocity (i.e. $\mathrm{P}-\mathrm{V}$ ) are varied through a series of experiments (single bead on plate, single layer pads, multi-layer pads, components and component features). Those experiments are combined with finite element thermal modeling of the melt pool geometry to define regimes of good quality deposits (e.g., avoiding lack of fusion, avoiding keyholing, ${ }^{36}$ increasing build rate, increasing process precision) across wide ranges of process variables. Figure 5 shows a recently developed $\mathrm{P}-\mathrm{V}$ map $^{35}$ for Ti-6Al-4V produced for electron beam (i.e. Arcam) single bead or raster deposits, while laserbased (i.e. EOS) deposits of Ti-6Al-4V, IN718, IN625, AlSi10Mg, CoCrMo, maraging steel and stainless steel are also in the various stages of being mapped. Maps of these powder fusion experiments are being correlated with surface roughness $^{37}$ and mechanical property measurements ${ }^{11,12}$ being performed at CWRU. In addition to changes to the bead quality shown in Fig. 5, changes to the surface roughness are also evident in different regimes of $\mathrm{P}-\mathrm{V}$ space. ${ }^{37}$ Surface roughness of asdeposited surfaces and/or internal passages may be particularly important for $\mathrm{HCF}$ and/or fluid flow applications.

In addition, mapping process outcomes across IN625, IN718, stainless steel, Al-Si-10Mg and cobalt chrome alloys are being conducted at CMU (e.g. Ref. 34). The full range of beam powers and travel speeds in typical AM processes (Fig. 6), is also being addressed. ${ }^{31}$ Building on earlier work, ${ }^{38,39}$ process mapping is also being applied to the feedforward and feedback control of microstructure in AM processes through the mapping of thermal conditions (e.g. cooling rates) at key temperatures across process variable space. Figure 7 gives an example ${ }^{40}$ of feedforward capability, where Ti-6Al-4V beta solidification microstructure (beta grain width) is controlled across three specimens through predetermined changes in process variables to yield grain widths that are roughly twice and three times the smallest grain width value of $91 \mu \mathrm{m}$. Where this figure demonstrates control of microstructure size across different specimens, recent results have demonstrated the feedforward control of microstructure size with location within single specimens.

\section{IN SITU PROCESS MONITORING AND FEEDBACK CONTROL}

In situ process monitoring and control are one of the key evolving areas that could impact qualification and certification of parts where quality demands are extremely high, such as aerospace and medical devices. The ability to produce multiple parts consistently across machines, operators, and manufacturing facilities could require the integration of various process monitoring and measurement tools. While careful and consistent process control can limit variability, the lack of adequate process measurement methods hinders more widespread use of the technology. Currently, process control based on heuristics and experimental data has only yielded limited improvements in part quality. As documented in a recent NIST report, traceable dimensional and thermal metrology methods must be developed for real-time closed-loop control of AM processes. ${ }^{41}$

Variability in AM machines and/or beam source/material interactions can create inconsistency in the microstructure, presence of defects, and variability in the mechanical performance. While in situ monitoring has been used in the past for DED, its use in the PBF processes is challenging due to limited access to the melt pool to enable imaging which is further complicated by the higher process velocity (Fig. 6). Recent attempts on process monitoring of $\mathrm{PBF}$ focused on defect detection and melt pool characterization that can be interrogated in situ. Melt pool monitoring is being used to capture the distribution of temperature within deposited layers in order to generate a heat map that can be compared to melt pool size. ${ }^{42,43}$ However, high bandwidth data acquisition (e.g. $1000 \mathrm{~s}$ of $\mathrm{Hz}$ ) and processing can generate enormous datasets that are difficult to manage while also requiring enormous amounts of data storage (e.g., $1000 \mathrm{~s}$ of 


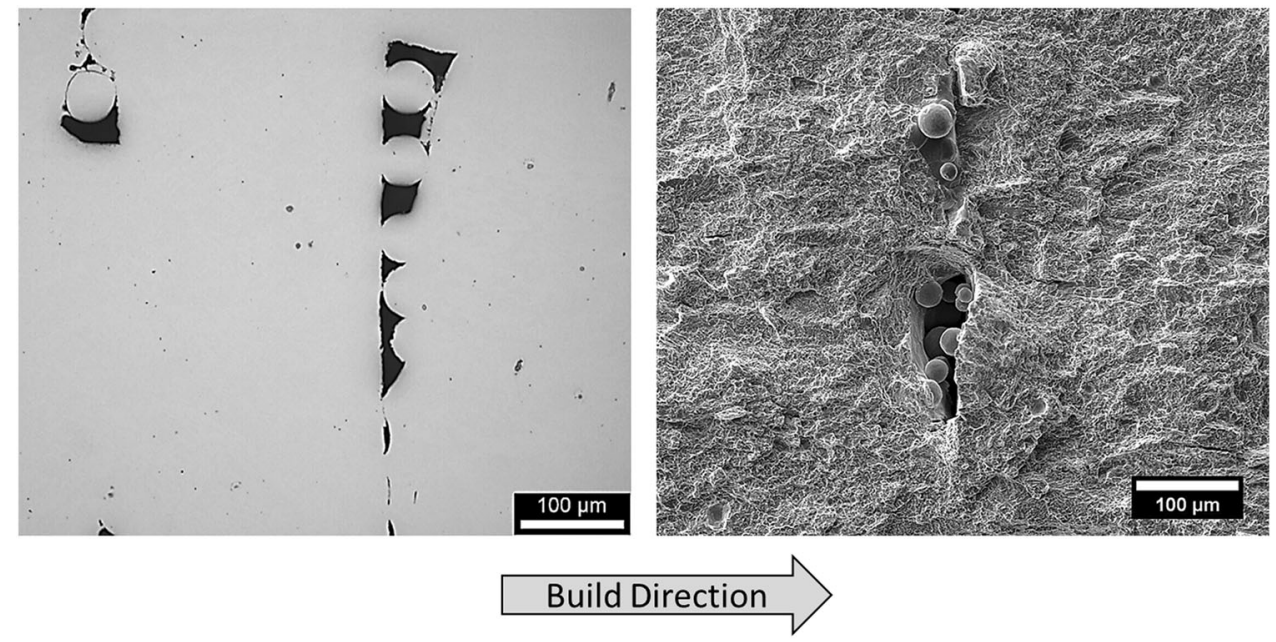

Fig. 8. Examples of lack of fusion: (a) metallographic cross-section, (b) fracture surface of as-deposited EBM Ti-6Al-4V tested in fatigue to failure. Defects shown present perpendicular to the build orientation in both cases.

GB). Nonetheless, various machine OEMs have begun to deploy process monitoring options for their equipment. One example, Concept Laser ${ }^{\mathrm{TM}}$, provides a quality assurance monitoring system (e.g., QMmeltpool 3D) that intends to detect processing defects at early stages, thereby providing a means for process optimization. ${ }^{42}$ In the next generation of machines under development, one of the desires is the retention of $x-y$ location information for all data throughout the build, thereby permitting the generation of a high-resolution 3D rendering of sensor signals. Ultimately, this may provide a quality assurance diagnostic similar to non-destructive testing (NDT) akin to computed tomography. Comparable systems are also being provided by other vendors such as Arcam ${ }^{\mathrm{TM}}$ (LayerQam), SLM Solutions ${ }^{\mathrm{TM}}$, and $\mathrm{EOS}^{\mathrm{TM}}$. As indicated in recent reviews, ${ }^{41}$ while process monitoring is necessary and has received significant interest, this technology for PBF is still in its infancy.

In the research community, feedback control approaches are being pursued at CMU in collaboration with significant efforts on process sensing. For the LENS process, indirect control of microstructure through thermal imaging and control of the melt pool is being pursued with Penn State and Stratonics through the linking of observable melt pool dimensions to the formation of microstructural features. Thermal control of the Arcam process is being implemented through thermal imaging of the entire build after layers are fused via an infrared system installed at the University of Texas at El Paso. CMU-developed process maps are being used to prescribe in-process changes in beam power and/or beam velocity to compensate for changes in average temperature in the build, yielding consistent microstructure sizes with part height. LLNL ${ }^{44}$ is also leading various modeling and simulation activities including melt pool monitoring.

\section{MICROSTRUCTURE AND DEFECT CHARACTERIZATION/QUANTIFICATION}

The performance of an AM part is directly affected by the underlying microstructure that is a permanent record of the processing pedigree. While the process mapping studies outlined above for Ti$6 \mathrm{Al}-4 \mathrm{~V}$ appear to be successful in mapping coarse microstructural features during solidification (e.g., beta grain size), additional emphasis is needed on solid state phase transformations that occur during subsequent cooling to room temperature as well as any thermal transients that occur during the build. The flexibility of producing complicated geometries by AM will require the ability to change locationspecific processing parameters to optimize the powder melting and solidification rates towards producing parts free of defects and with desired microstructural features over a range of size and length scales. Microstructure heterogeneity (morphology, crystallography, and alignment with build direction) is expected and perhaps desired in some cases. While location-specific microstructure heterogeneities are to be expected/desired in parts with complicated geometries due to geometrical heterogeneities, location-specific microstructure variability ${ }^{11}$ has been reported in geometrically homogeneous primitive shapes (e.g., cuboids). While defects (e.g., lack of fusion, voids) detected in previous work ${ }^{11}$ and shown in Fig. 8 are main constituents of the microstructure, they will be discussed in a separate section due to the different methodology of characterization (i.e. $\mu \mathrm{CT}$ scans) as well as the need to link them to probabilistic approaches for fracture, fatigue, and lifing predictions.

Various works have shown that electron beam AM of Ti-6Al-4V parts with a preheated powder bed produce solidification rates and beta grain sizes consistent with that shown in Figs. 5 and 7, 
(a)

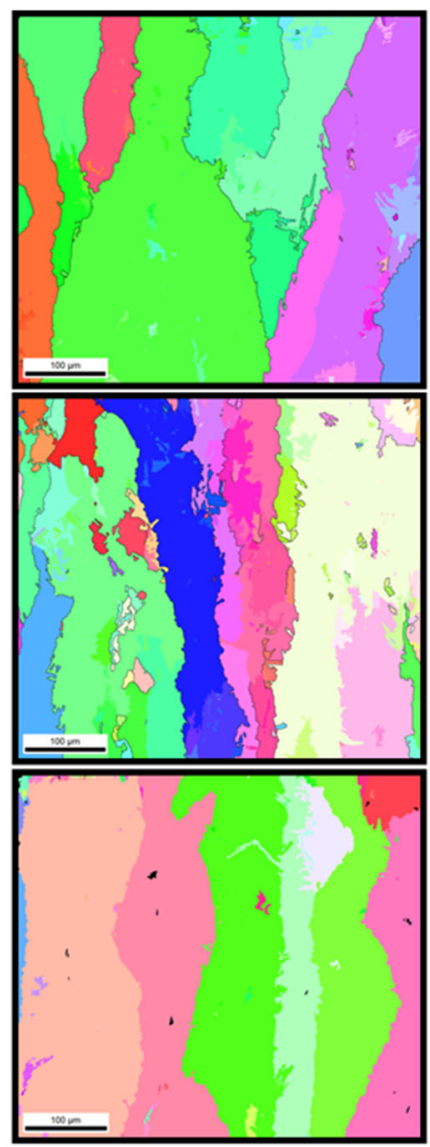

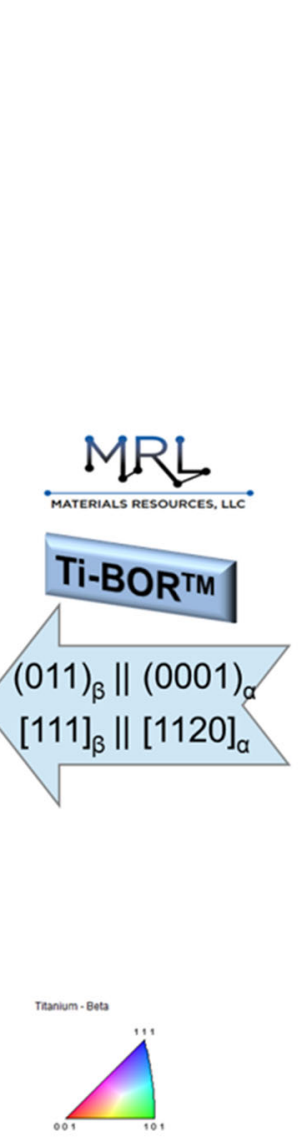
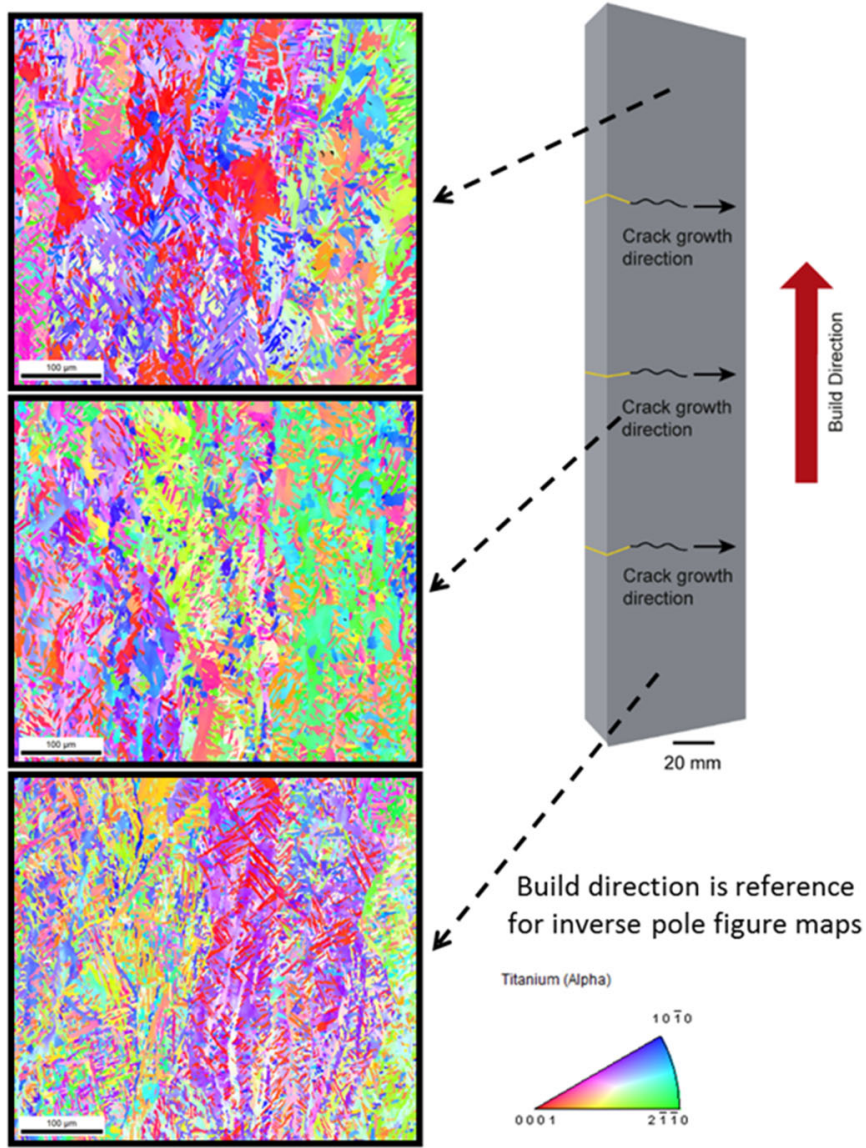

(b)
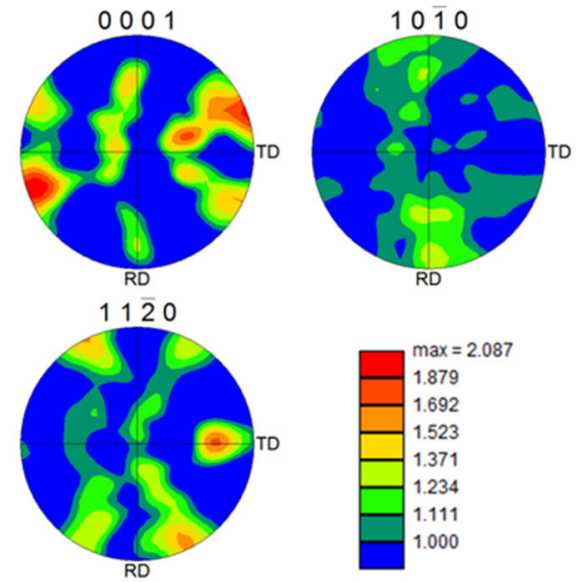

$15,000 \mu \mathrm{m} \times 10,000 \mu \mathrm{m}$
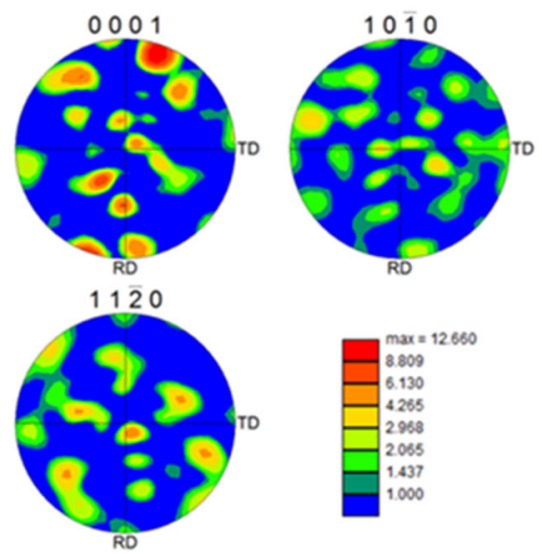

$500 \mu \mathrm{m} \times 500 \mu \mathrm{m}$

Fig. 9. (a) Build direction IPF maps for the alpha phase (right) and reconstructed beta phase (left) in the bottom, mid-height and top of the EBMdeposited Ti-6Al-4V SL sample: ${ }^{11}$ (b) comparison between texture from large area EBSD scans (left) and small area EBSD scans (right) showing the strong texture in the small area scans.

depending on the $\mathrm{P}-\mathrm{V}$ combinations employed. However, the finer scale microstructural features post-solidification also depend on cooling rate as well as any thermal transients that occur during multi-layer deposition that may produce a basketweave microstructure with alpha-lath thicknesses less than $1 \mu \mathrm{m}$. In contrast, laser-based techniques without preheated powder beds produce more rapid solidification and cooling rates in the solid state, along with the observation of 


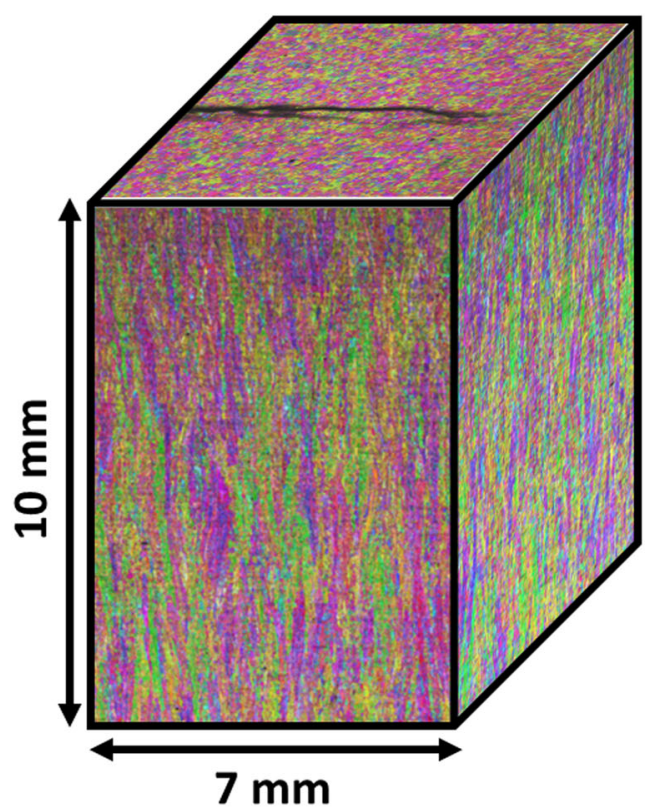

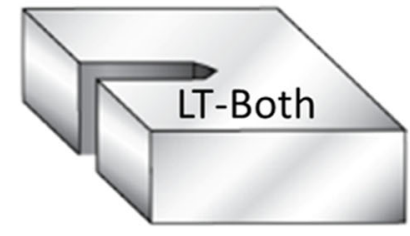

(Build direction)

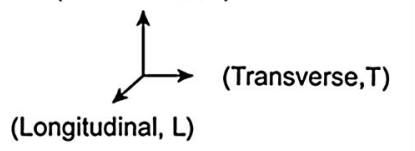

(Longitudinal, L)

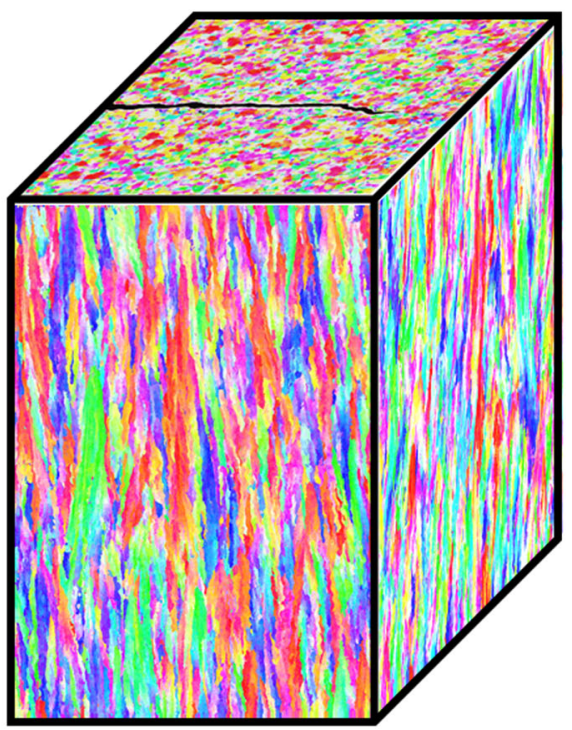

Fig. 10. Large area 3D-EBSD capturing the area around crack propagation in an LT-BOTH sample test. EBSD captures a volume covering a $7 \mathrm{~mm} \times 7 \mathrm{~mm} \times 10 \mathrm{~mm}$ region (left alpha phase, right reconstructed beta phase using TiBOR ${ }^{\mathrm{TM}}$ [www.MiCloud.AM]. The sample orientation and crack path direction (perpendicular to the build direction) captured on the surface of the LT-BOTH ${ }^{11}$ sample are shown (center).

martensitic microstructures ${ }^{37}$ in the as-deposited condition. In the case of electron beam AM processing where the solidification/cooling rates are somewhat slower, the alpha laths (hcp) are produced via phase transformation of prior beta (bcc) upon cooling below the beta transus $\left(\sim 1000^{\circ} \mathrm{C}\right)$, while the morphology and crystallography of the prior beta grains are dependent on the cooling rate and build direction. ${ }^{38,45}$ As such, electron backscatter diffraction (EBSD) techniques are often used first to capture the crystallography and morphology of the room temperature alpha phase, followed by reconstruction of the prior beta phase using the Burger orientation relationship between alpha and beta, ${ }^{46}$ as explained below.

\section{LARGE AREA BSE/EBSD, MACRO/MICRO TEXTURE EVOLUTION}

Practical microstructure characterization requires designing the inspection volume to be large enough to capture relevant statistics about the feature of interest (FOI ${ }^{45}$ at a high enough resolution for the lowest possible cost (i.e. least recording time). In AM parts made of Ti-6Al-4V by electron beam techniques, one of the major FOI is the high-temperature beta grain size. However, the beta phase has a small volume fraction at room temperature, ${ }^{45}$ which makes it difficult/expensive to record using EBSD. Alternatively, the alpha phase is recorded at room temperature, and the beta phase is then reconstructed from the alpha phase using the Burger orientation relationship [TiBor @ www.MiCloud. $\mathrm{AM}]$, although the inspection volume must be selected carefully as demonstrated below.
Figure 9a shows build direction inverse pole figure (IPF) maps for alpha phase (right) and reconstructed beta phase (left) for an as-deposited tall build (i.e. $100 \mathrm{~mm}$ ) of EBM Ti-6Al-4V, using EBSD data collected from $500 \mu \mathrm{m} \times 500 \mu \mathrm{m}$ areas. Analyses of the data from this scan area did not reveal obvious variation in the alpha phase microstructure between the start (i.e. bottom) of the build and the end (i.e. top) of the build shown in Fig. 9a. However, the IPF maps of the reconstructed beta revealed some differences between the start and end of the build, highlighting the importance of inspecting the microstructure of beta phase after AM. Further inspection of the beta reconstruction in Fig. 9a (left) also shows that only a limited number of beta grains (e.g., <5) have been captured within this scan area, which does not result in reliable statistics to link processing-microstructure, and performance for qualification purposes.

In order to address this and illustrate the importance of scan area, our EBSD data generation has been designed to satisfy two conditions: (1) high enough resolution to record alpha orientations from thin laths and (2) covering an area that is large enough to record data from many prior beta grains for reliable statistics, recognizing that each beta grain can be multiple millimeters in size depending on the AM process and $\mathrm{P}-\mathrm{V}$ conditions employed. While many modern scanning electron microscopes can record EBSD scans from large areas (e.g., $5 \mathrm{~mm} \times 5 \mathrm{~mm}$ ) at high resolution (e.g., $1 \mu \mathrm{m}$ step size), analyzing large files (e.g. 25,000,000 alpha orientations) is a challenge for many commercial software running on standalone PCs. To address 

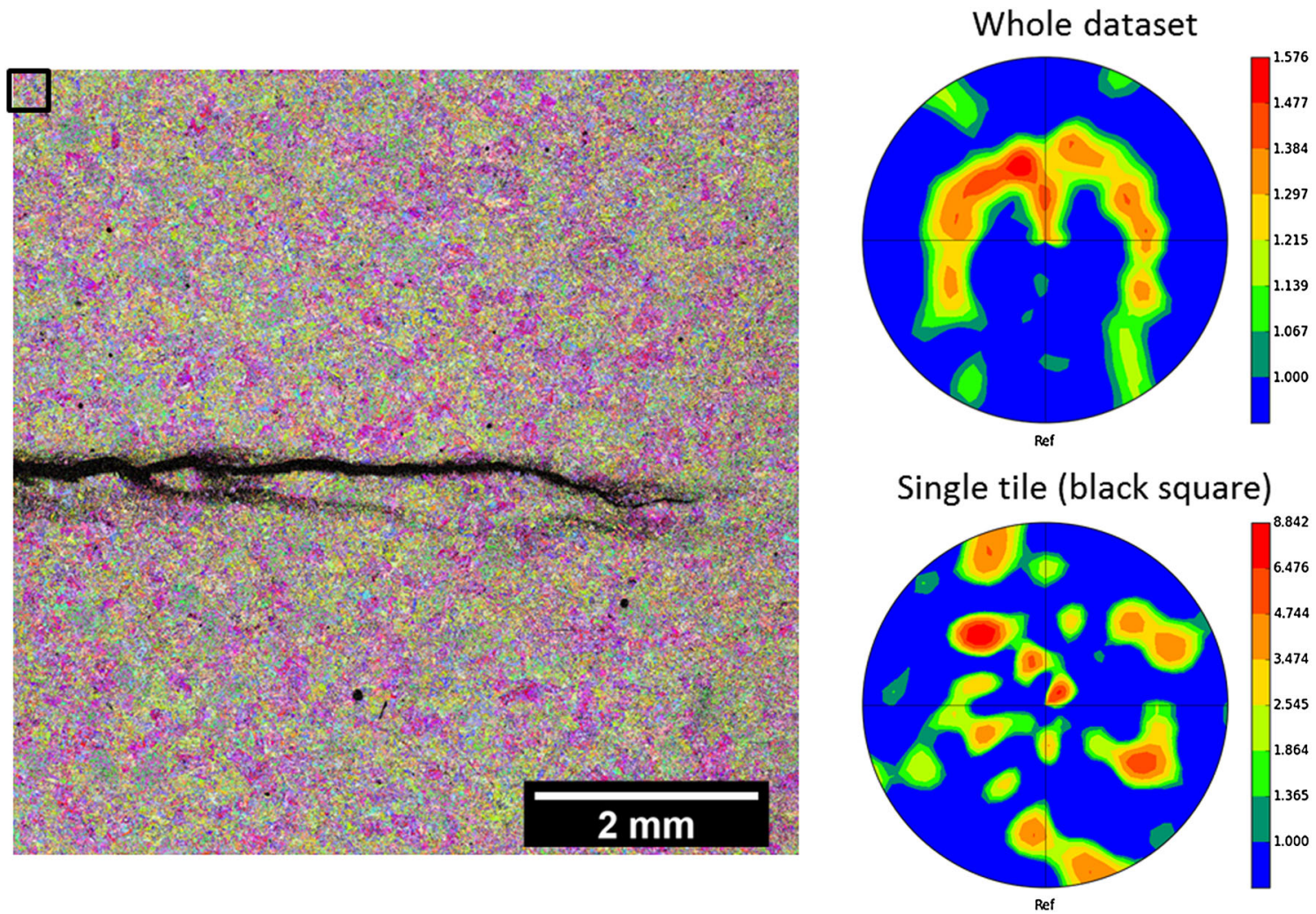

Fig. 11. Top surface of 3D-EBSD image shown in Fig. 10 that captures the crack growth in an LT-BOTH ${ }^{11}$ sample. Build direction IPF map for alpha phase (left) and the associated 0001 pole figure for the whole scan (right top) and a single $250 \mu \mathrm{m} \times 250 \mu \mathrm{m}$ tile shown at top left, (0001) pole figure at right bottom, where the build direction is parallel to the pole figure normal direction. It is necessary, due to the coarseness of the microstructure, to capture data over a large area in order to accurately represent the total texture.

this challenge, many tools were developed within MiCloud.AM to conduct data analytics on Big EBSD datasets (as large as 100,000,000 orientations covering $10 \mathrm{~mm} \times 10 \mathrm{~mm}$ areas at $1 \mu \mathrm{m}$ resolution) using various data mining techniques and cloud computing.

Figure 9a and b clearly shows that both the morphology of the prior beta and texture of the alpha phase are unreliably presented in commonly used $500 \mu \mathrm{m} \times 500 \mu \mathrm{m}$ EBSD scans for AM Ti-6Al$4 \mathrm{~V}$ parts, in contrast to the large EBSD scans shown in Fig. 9b. In particular, analyses of the pole figures of the alpha phase obtained from a $500 \mu \mathrm{m} \times 500 \mu \mathrm{m}$ region showed much sharper texture intensity ( $\sim 13-21$ times random) than has been recorded by $150,000 \mu \mathrm{m} \times 10,000 \mu \mathrm{m}$ scans ( $\sim 2$ times random) (Fig. 9b). In addition, the locations of various texture components were drastically different.

Large area scans may be particularly relevant for correlating fracture paths in AM samples/parts as well as the orientation dependence of microstructure and fracture properties between different build orientations. This is first demonstrated by comparing the tall build in Fig. 9a to a different build orientation shown in Fig. 10 where large EBSD scans were similarly conducted to produce the $3 \mathrm{D}$ images of the as-deposited material in Fig. 10. The reconstructed beta grains in Fig. 10 (right) are consistent with those shown along the build direction in Fig. 9a (right). Figure 10 was constructed from an as-deposited sample that was fracture tested in the LT-BOTH orientation ${ }^{11}$ shown, and a crack was captured in the regions analyzed. It is worth noting that the alpha texture around the crack from a $7 \mathrm{~mm} \times 7 \mathrm{~mm}$ scan area was only $\sim 1.6$ times random (Fig. 11 (top right)) in contrast to that shown for the 250- $\mu \mathrm{m}$ scan area shown in Fig. 11 (bottom right), in agreement with the findings shown earlier in Fig. 9 even with the $90^{\circ}$ difference in the build direction. These preliminary observations reveal the importance of conducting large area EBSD scans for accurate qualification based on linking processing-microstructure-performance in Ti-6Al-4V AM parts, as well as correlating microstructure features to the fracture path, as discussed below.

\section{MECHANICAL PROPERTY MEASUREMENTS (FRACTURE/FATIGUE)}

One of the key aspects for qualification of AM parts/components is the mechanical performance that requires a wide range of mechanical testing/ characterization. Measurement science for the AM industry to determine material properties in a 


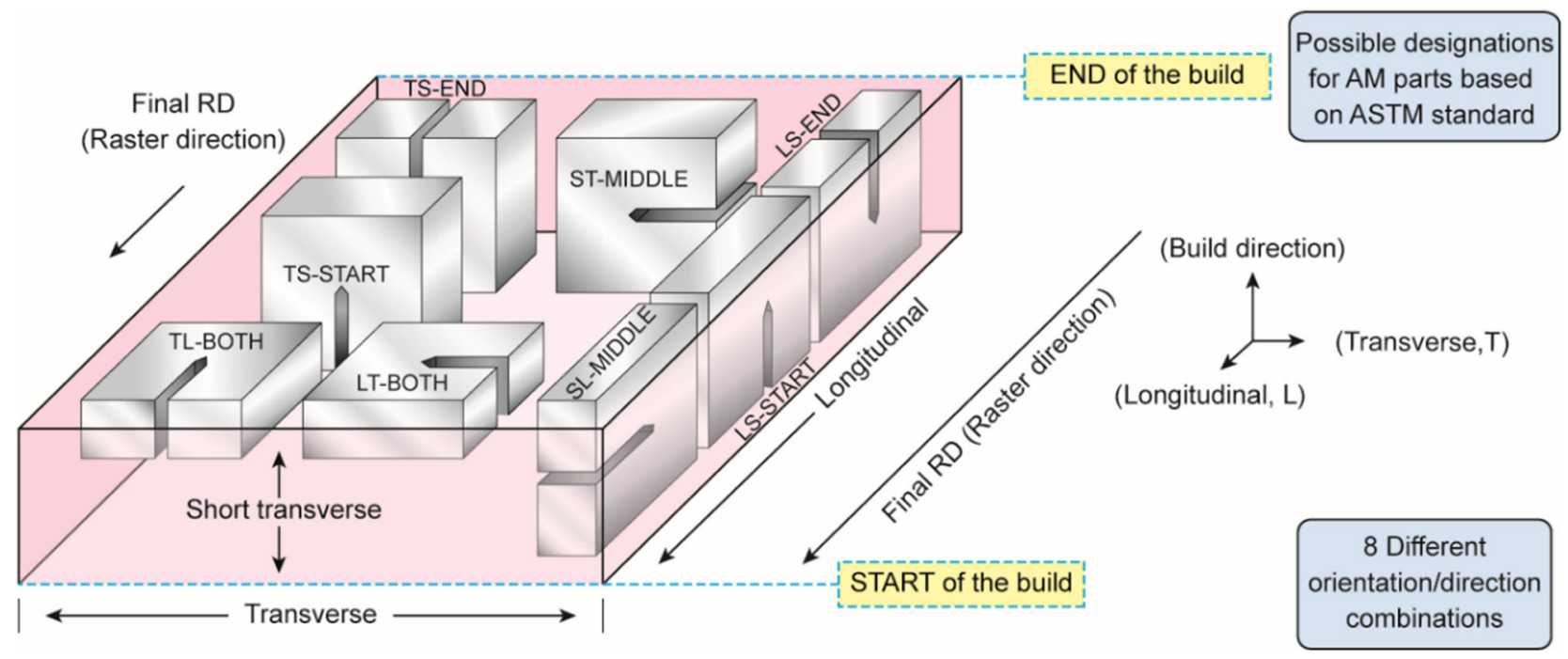

Fig. 12. Possible ASTM nomenclature illustrating crack growth directions with respect to the build direction. ${ }^{11}$

standardized way has gathered a significant amount of interest over the last 3 years. ${ }^{41,47,48}$ Currently, there are no consensus-based public standards in this area, except for a few examples related to terminology and data file formats. ${ }^{49,50}$ The ASTM International Committee F42 on Additive Manufacturing Technologies and the International Organization for Standardization (ISO) TC261 Committee on Additive Manufacturing have started separately, and in some cases jointly, standard development to address this deficiency.

Most recently, America Makes co-sponsored an event $^{51}$ to help coordinate U.S. standards development activities for AM. Key standards developing organizations (SDOs), including ASTM, SAE, ASME, SME, AWS, etc., along with a number of OEMs, gathered to discuss and facilitate collaborative efforts with the goal of initiating a dialogue on joint standards development for AM. These activities are being viewed as one mechanism that can facilitate product qualification and certification. For example, aero engine parts could be certified by FAA while biomedical parts could be certified by FDA. The overarching goal of these coordination efforts is to produce a roadmap that will minimize the amount of overlap activities across the various standardization organizations.

Static properties (e.g., YS, UTS, etc.) can be measured using already developed standards that are being modified to accommodate the unique orientations and aspects provided by AM processing. ${ }^{50,52}$ However, when fracture-critical properties are a concern, utilizing conventional methods and standards may produce some challenges and uncertainty, ${ }^{53}$ particularly with regard to measuring location-specific fracture properties. Examples are the measurement of fracture toughness, fatigue crack growth and high cycle fatigue properties $^{11,12,35}$ where lack of nomenclature and designation is evident, although ASTM F42 has started to address these needs. ${ }^{54}$ In particular, a registered ASTM work item is being proposed to provide possible approaches for mechanical testing characterization ${ }^{55}$ as shown in Fig. 12.

\section{NON-DESTRUCTIVE INSPECTION/ EVALUATION $(\mu \mathrm{CT})$ OF DEFECT DISTRIBUTION}

There are no voluntary consensus standards for NDT of AM parts either in ASTM E07 or F42; however, an ASTM work item has been recently registered to address the needs for AM as a guideline ${ }^{56}$ based on other reports where NDE has been identified as a universal need for all aspects of AM. ${ }^{7}$ One of the key barriers is that existing NDE methods are not optimized for AM processes and materials, although it can be used as one of the validation/qualification tools. Figure 13 is provided to demonstrate how micro-computerized tomography $(\mu \mathrm{CT})$ can be used in as-deposited (or postprocessed) materials to detect various defects. Typical defect types for AM processes include: layer defects, lack of fusion (LoF), isolated/clustered porosity, voids, and high-density inclusions/contaminations. Some of these are identified in Fig. 13 for an as-deposited Ti-6Al-4V bend bar with dimensions $10 \mathrm{~mm} \times 20 \mathrm{~mm} \times 100 \mathrm{~mm}$ in an LT-BOTH (cf. Fig. 12) sample tested in previous work. ${ }^{11}$ The linear LoF defects, similar to that shown in Fig. 8, are clearly evident in addition to various other randomly located porosity. While hot-isostatic pressing may be capable of closing isolated porosity, LoF defects are more problematic depending on their location. However, one key advantage of $\mu \mathrm{CT}$ relates to the ability to detect the range of defects 


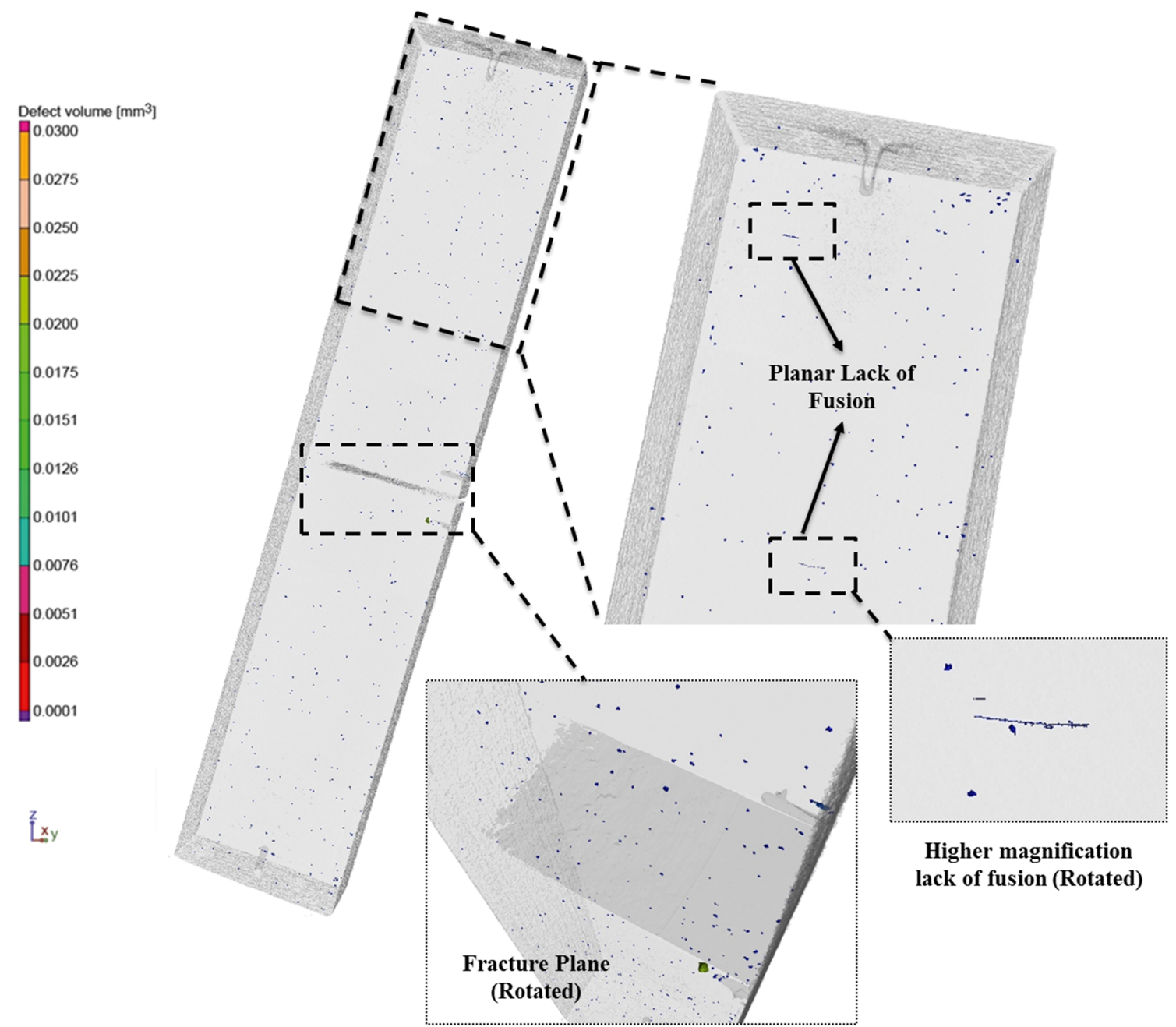

Fig. 13. Computed tomography image of as-deposited and subsequently fractured Ti-6Al-4V sample with dimensions $10 \mathrm{~mm} \times 20 \mathrm{~mm} \times 100 \mathrm{~mm}$. Crack growth is in the LT-BOTH orientation. ${ }^{11}$ Planar lack of fusion defects and random porosity is evident at various locations. Lack of fusion defects detected are of similar size to that shown in Fig. 8 and reported previously. ${ }^{11}$ Resolution limit for this scan was 10-20 $\mu \mathrm{m}$. Finer resolution is possible with smaller sample size/volume.

indicated as well as their location while also enabling the confirmation of the effectiveness of post-processing treatments.

\section{MICROSTRUCTURAL/MECHANICAL/ DEFECT INTERACTION OR COMPETITION}

Figure 14 is provided to highlight the recent observations ${ }^{11,12,35}$ of location-dependent properties in as-deposited $\mathrm{Ti}-6 \mathrm{Al}-4 \mathrm{~V}$ produced by electron beam powder bed processing in the context of the present overview. Fracture toughness experiments conducted in three different locations on a tall build (i.e. $20 \mathrm{~mm} \times 10 \mathrm{~mm} \times 100 \mathrm{~mm}$ ) revealed significant differences. Ongoing work ${ }^{57-59}$ is characterizing the defect density and type as well as microstructural features using some of the techniques outlined in this overview. Fracture-critical properties are affected by a variety of factors and two of the dominant factors are defect density and microstructure variation. Some properties (e.g.,
$\mathrm{HCF}$, toughness) are very sensitive to defects as these provide potent fracture nucleation sites ${ }^{12,60}$ as well as preferred regions for crack growth while other dominant factors include microstructural features at a range of size and length scales depending on the property of interest. ${ }^{61}$ In the example shown in Fig. 14, while a lower defect density was present toward the end of the build in the region of high toughness, microstructural details were also different from the start to the end of the build (e.g., Fig. 9) thereby preventing a direct correlation. This highlights the continuing need for a comprehensive examination of various factors (e.g., defects, microstructure, residual stress, etc.) controlling the mechanical behavior of AM materials while also integrating modeling and experimentation efforts to produce materials/parts with desired location-specific properties. ${ }^{35,58,59}$ This emphasizes the need of an ICME approach for qualification. 


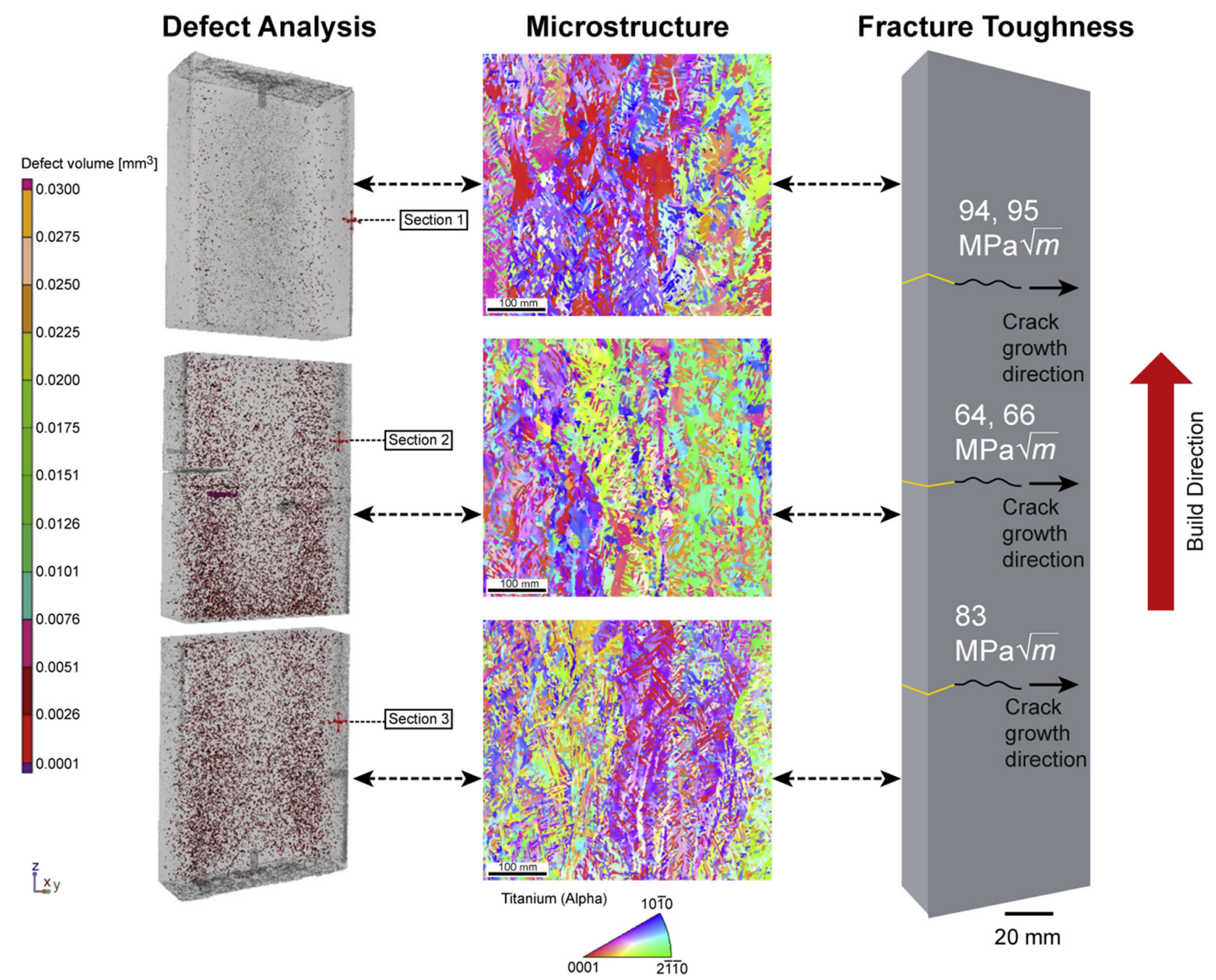

Fig. 14. Location-dependent properties in as-deposited EBM Ti-6Al-4V materials are affected by convoluted interactions between defectdominated and microstructure-dominated contributions.

\section{PROBABILISTIC MODELING OF FRACTURE AND FATIGUE}

While the goal of producing defect-free parts in as-deposited materials remains an area of extreme interest, inspection processes (e.g., x-ray tomography, UT, acoustics, etc.) and various post-processing techniques (e.g., HIP, heat treatment, etc.) may continue to need to be implemented for use in fracture-critical applications. However, non-critical locations (i.e. low stress, strain) in fracture critical parts may not require the same damage tolerance/ properties required in highly stressed areas (Fig. 2). There has been increased use of probabilistic methods for design assessment of reliability with inspection (DARWIN) ${ }^{62}$ for a variety of processing techniques (e.g., casting, forging, heat treatment, etc.) to deal with local variations in microstructure/ defects/properties in lifing estimates. Programs such as DARWIN and others have been shown to reduce significantly computation time compared to other methods (e.g., Monte Carlo). In addition, proper sampling strategies can be employed to achieve a desired sampling accuracy result for a given confidence interval, thereby focusing on variables that should have the most effect on risk reduction. ${ }^{62}$ While probabilistic approaches have been used successfully in previous work for predicting thresholds for cracking in commercial aluminum alloys, ${ }^{63,64}$ such approaches would also appear to be useful for modeling/predicting the effects of changes in AM process variables on subsequent performance as well as modeling location-specific properties.

\section{MICROSTRUCTURE INFORMATICS, MODELING AND SIMULATION-AN ICME APPROACH}

Due to the complicated nature of the AM process, a coherent integration between various stages and scales of modeling the materials behavior and the 
corresponding measurements is critically needed within the framework of the Materials Genome Initiative (MGI) ${ }^{65-67}$ and ICME. ${ }^{25,26,68-74}$ In particular, AM will benefit from the ICME goal of enabling optimization of materials, manufacturing processes, and component design long before components are fabricated by integrating computational processes involved into a holistic system. Developing and implementing such a system will enable a more efficient qualification process using big data science approaches. ${ }^{71,72}$

As a demonstration of the practical implementation of an ICME approach, the team involved in this effort integrated efforts from academia, OEMs, and a small business all working on various projects with different funding sources. However, all members recognized the value of collaboration and integration of results obtained using various tools. To enhance such a collaboration and integration of efforts, three major elements were identified: (1) a part that could be produced, (2) datasets to be collected, and (3) a platform to consolidate all the data for analysis using state of the art data-mining algorithms. In addition, an efficient workflow ${ }^{45}$ is needed to promote transparency and efficient collaborations between materials experts and manufacturing/design specialists by providing an understanding of the various mesoscale heterogeneities that develop naturally in the workpiece as a direct consequence of the inherent heterogeneity imposed by the AM process.

While each team member was responsible for one or more of the items above, the communication was led by CWRU under various non-disclosure agreements that allowed the exchange of information while respecting the Intellectual property (IP) of each team member. To avoid any issues with proprietary designs, the team also selected to demonstrate such collaboration on rectangular coupons. Each team member maintained the details of characterization procedures while sharing the inputs and outputs for each process with the team. The shared data were provided in standard formats that are common in the public domain, such as ASCII files and images. A practical implementation of such a workflow has been deployed at www. MiCloud.AM as the first microstructure-based AM software-as-a-service (SaaS). It is designed on three main pillars: (1) data science protocols for efficient analysis of large datasets, (2) protocols for extracting reduced descriptions of salient microstructure features for insertion into simulations (e.g., regions of homogeneity), and (3) protocols for direct and efficient linking of materials models/databases into process/performance simulation $\operatorname{codes}^{45}$ (see Fig. 2).

In the initial phases of this collaboration, data generated/provided to CWRU were then imported to MiCloud.AM for data mining. The results of microstructure informatics and data mining (i.e. data products) were then shared with the rest of the team towards establishing correlations for qualification. Such a data flow is made possible via using MiCloud.AM with multiple functionalities including Big Data storage, analytics, and visualization capabilities.

Development of accurate AM modeling and simulation tools is an important fundamental building block for an ICME approach for AM. The availability of good validated physics-based modeling and simulation tools decreases the need for experimental testing of technologies and processes and gives product designers a predictive capability to optimize part designs. Accurate models are also vital for developing the required control technologies and software for AM, developing standards, and establishing qualification/certification procedures.

The accuracy of predictions using various simulation tools is heavily dependent on the availability of comprehensive data on materials and deposition processing for calibration, validation, and verification processes. While there have been many recent attempts to develop such models, ${ }^{75}$ the complicated nature of the AM process affect the current accuracy of predictions for developing comprehensive simulation-based qualification tools. Furthermore, to increase the accuracy of predictions, these tools require a better understanding of the fundamental processes and physical phenomena that underlie AM feedstock inputs, approaches, and technologies which are not possible without generating and analyzing a large amount of data and sharing them among multiple collaborating companies as described herein.

\section{QUALIFICATION/CERTIFICATION PATHWAY}

Statistically-based legacy qualification processes for metallic materials require extensive testing that may cost millions of dollars and take up to 15 years to complete. ${ }^{76}$ This approach is not practical for qualifying AM parts that are known for drastic variability in processes and processing parameters within each process. On the other hand, modelbased qualification requires a smaller number of tests to validate the model. However, the rapid and complicated AM process adds many challenges to developing physics-based models with repeatability and reproducibility of predictions across varying processes and process parameters. The proprietary nature of process controls that are imposed by commercial machine manufacturers drastically reduces the availability of data needed to calibrate and validate models that are necessary for the model-based qualification.

Recently, Dave Abbott of $\mathrm{GE}^{77}$ demonstrated the success of GE in certifying the GE9X T25 Sensor and the LEAP Fuel Nozzle without the need for new qualification standards. While this approach is very promising and an excellent example for parts that are produced in mass production, it will be crucial to establishing its implementation on small(er) batches of other AM parts. 
In the realm of components or repairs produced by direct deposition of Ti-6Al-4V, AMS standard $4999 \mathrm{~A}^{78}$ prescribes certain conditions for feedstock composition, atmosphere, and post-processing (i.e. HIP and/or heat-treatment) to be used in production, as well as minimum standards for tensile and fracture toughness properties in finished products and standardized acceptance testing procedures for each production run (consisting of composition, mechanical properties along and perpendicular to the build direction, microstructure and surface contamination, and NDT by ultrasound and radiography) along with re-test and rejection criteria. The standard also provides for a qualification pathway consisting of several stages: (1) source qualification, including $>50$ tensile test results from each principal build direction (i.e. $X, Y, Z$ ) covering 3 different configurations and 3 different feedstock heats and meeting specified property and variation limits; (2) approval of deposition or deposition/geometry parameters, with sufficient tensile and strain-controlled fatigue test coupons produced to cover the space of processing and geometrical parameters in the component, including deposition power and feed rate, feedstock, deposit height, width, and length, inclination angle, scan strategy, intersection angle and orientation, etc.; and (3) production qualification by destructive testing of one or more production-level parts by $>12$ tensile tests in each direction. Upon qualification, each of the production parameters is fixed, with any deviations requiring additional testing.

The qualification procedure prescribed in AMS4999A is a classic example of statisticallybased qualification, wherein the uncertainty in the production of a particular component is understood and mitigated by massive upfront testing, followed by ongoing quality control testing during production. It is very similar to the procedure that has long been used for aerospace castings, ${ }^{79}$ where any other than very minor deviation from the qualified procedure triggers a re-qualification process. While such a procedure is suitable for serial production of numerous identical parts (such as the fuel nozzle mentioned above), it represents a high barrier for production of customized, repair, and low-volume components where AM techniques are often most desirable, and demonstrates a clear need for holistic, ICME-based qualification schemes that encompass pre-process, in-process, and post-process data to facilitate demonstration of part suitability according to a "qualify as you go" paradigm. ${ }^{80}$

\section{SUMMARY AND FUTURE TRENDS}

This article is provided as an attempt to capture an overview of the various challenges to be considered in the qualification of metal AM. These include the need for various modeling and experimental activities, along with the integration of such efforts at the size and length scales relevant for intended applications. In addition, a proposed example of multi-organization collaboration towards addressing some of the qualification challenges was demonstrated via an implementation of an ICME approach via BigData analytics and cloud computing.

\section{ACKNOWLEDGEMENTS}

This work was partly supported by America Makes, the National Additive Manufacturing Innovation Institute, under Project No. 4009: "Rapid Qualification Methods for Powder Bed Direct Metal Additive Manufacturing Processes" through Contract No. FA8650-12-2-7230 and it is highly appreciated. Additional support was provided by two ASTM International Scholarship Awards (M. Seifi) and the Armington Professorship (J. J. Lewandowski). Various discussions with academic team members as well as industrial partners and government laboratories during monthly webinars are appreciated. These include four other university partners (NCSU, CMU, U of L, and WSU), five industrial partners (Lockheed Martin, Pratt \& Whitney, GE, Kennametal, and Bayer) and two government laboratories (ORNL and NIST). M. Seifi appreciates various discussions with ASTM F42/ E08/E07 committee members. A. Salem and EBSD work are supported under a NAVAIR SBIR “Adaptive Microstructure-Based Approach for Rapid Qualification by Similarity of Ti-6Al-4V Parts Manufactured by Additive Manufacturing (AM) Techniques" under Contract No. N6833515C0209. The help of Dr. Daniel Satko of MRL in generating large-scale EBSD data is appreciated. The tomography analysis shown in Fig. 13 was conducted by Ms. Whitney Yetter at GE Inspection Technologies while the tomography analysis shown in Fig. 14 was conducted by Mr. Daniel Rankin at YXLON, a division of COMET Technologies, Inc.

\section{REFERENCES}

1. ASTM Standard F2792, ASTM Book of Standards (West Conshohocken: ASTM International, 2012).

2. T. Caffrey and T. Wohlers, Wohlers Report-3D printing and Additive Manufacturing State of Industry (2015).

3. C.L. Weber, V. Pena, M.K. Micali, E. Yglesias, S.A. Rood, J.A. Scott, and B. Lal, Inst. Def. Anal. 6 (2013).

4. D.L. Bourell, M.C. Leu, and D.W. Rosen, Roadmap for Additive Manufacturing: Identifying the Future of Freeform Processing (2009).

5. C.B. Williams, T.W. Simpson, and M. Hripko, NIST Technical Note 1823-Additive Manufacturing Technical Workshop Summary Report (2013).

6. Energetics Incorporated, Measurement Science Roadmap for Metal-Based Additive Manufacturing-Workshop Summary Report (2013).

7. J.M. Waller, B.H. Parker, K.L. Hodges, E.R. Burke, J.L. Walker, and E.R. Generazio, Nondestructive Evaluation of Additive Manufacturing State-of-the-Discipline Report, (2014).

8. W.E. Frazier, J. Mater. Eng. Perform. 23, 1917 (2014).

9. W.E. Frazier, D. Polakovics, and W. Koegel, JOM 53, 16 (2001).

10. W. Frazier, Solid Free Form Fabr. Proc. 717 (2010).

11. M. Seifi, M. Dahar, R. Aman, O. Harrysson, J. Beuth, and J.J. Lewandowski, JOM 67, 597 (2015). 
12. J.J. Lewandowski and M. Seifi, Annu. Rev. Mater. Res. 46 (2016).

13. Directorate-General for Research and Innovation, Horizon 2020 in Brief-The Framework Programme for Research and Innovation (2014).

14. Materials Science and Engineering Expert Committee (MatSEEC), Metallurgy Europe-A Renaissance Programme for 2012-2022 (2012).

15. RepAIR-Future RepAIR and Maintenance for Aerospace industry. [Online]. http://www.rep-air.eu/. Accessed 15 Sep 2015.

16. Reinforcing Additive Manufacturing Research Cooperation Between CMRDI and the European Research Area. [Online]. http://www.fp7-admera.org/. Accessed 15 Sep 2015.

17. AMAZE: Additive Manufacturing Aiming Towards Zero Waste \& Efficient Production of High-Tech Metal Products. [Online]. http://www.amaze-project.eu/. Accessed 15 Sep 2015.

18. AMCOR: Additive Manufacturing for Wear and Corrosion Applications. [Online]. http://www.amcor-project.eu/. Accessed 15 Sep 2015.

19. The European collaboration on Additive Manufacturing. [Online]. http://www.rm-platform.com/. Accessed 15 Sep 2015.

20. ManSYS: MANufacturing and supply chain management SYStem for Additive Manufacturing. [Online]. http://www. mansys.info/. Accessed 15 Sep 2015.

21. Industrial and Regional Valorization of FoF Additive Manufacturing Projects. [Online]. http://www.fofamproject.eu/. Accessed 15 Sep 2015.

22. Support Action for Standardisation in Additive Manufacturing. [Online]. http://www.sasam.eu/. Accessed 15 Sep 2015.

23. Development of Aero Engine Component Manufacture using Laser Additive Manufacturing. [Online]. http://www.merlinproject.eu/. Accessed 15 Sep 2015.

24. S. Draper, I. Locci, B. Lerch, D. Ellis, P. Senick, M. Meyer, J. Free, K. Cooper, and Z. Jones, 66th International Astronautical Congress (2015), pp. 1-9.

25. J. Allison, B. Cowles, J. DeLoach, T. Pollock, and G. Spanos, Integrated Computational Materials Engineering (ICME): Implementing ICME in the Aerospace, Automotive, and Maritime Industries (The Minerals, Metals \& Materials Society, 2013).

26. Integrated Computational Materials Engineering: A Transformational Discipline for Improved Competitiveness and National Security (The National Academies Press, 2008).

27. P.C. Collins, R. Banerjee, S. Banerjee, and H.L. Fraser, Mater. Sci. Eng., A 352, 118 (2003).

28. America Makes Project 4049, Economic Production of Next Generation Orthopedic Materials Through Powder Reuse in AM (2015). [Online]. https://americamakes.us/home-2/item/ 771-economic-production-of-next-generation-orthopedic-ma terials-through-powder-reuse-in-am. Accessed 15 Sep 2015.

29. America Makes Project 4028, A Database Relating Powder Properties to Process Outcomes for Direct Metal AM, (2015). [Online]. https:/www.americamakes.us/home-2/item/500-adatabase-relating-powder-properties-to-process-outcomes-fordirect-metal-am. Accessed 15 Sep 2015.

30. J. Gockel, J. Beuth, and K. Taminger, Addit. Manuf. 1-4, 119 (2014).

31. J. Beuth, J. Fox, J. Gockel, C. Montgomery, R. Yang, H. Qiao, P. Reeseewatt, A. Anvari, S. Narra, and N. Klingbeil, Solid Freeform Fabrication Proceedings (2013), pp. 655-665.

32. J. Gockel and J. Beuth, Solid Freeform Fabrication Proceedings (2013), pp. 666-674.

33. E. Soylemez, J.L. Beuth, and K. Taminger, Proceedings of 2010 Solid Freeform Fabrication Symposium (August, 2010), pp. 571-582.

34. C. Montgomery, J. Beuth, L. Sheridan, and N. Klingbeil, Proceedings of Solid Freeform Fabrication Symposium (2015), pp. 1195-1204.
35. M. Seifi, D. Christiansen, J.L. Beuth, O. Harrysson, and J.J. Lewandowski, Ti-2015: The 13th World Conference on Titanium (Wiley, 2016).

36. W.E. King, H.D. Barth, V.M. Castillo, G.F. Gallegos, J.W. Gibbs, D.E. Hahn, C. Kamath, and A.M. Rubenchik, J. Mater. Process. Technol. 214, 2915 (2014).

37. D. Christensen, M. Dahar, J. Beuth, and J.J. Lewandowski, Unpublished results (2015).

38. P. A. Kobryn and S. L. Semiatin, JOM, 40 (2001).

39. S. Bontha, The Effect of Process Variables on Microstructure in Laser-Deposited Materials (Dayton: Write State University, 2006).

40. S.P. Narra, R. Cunningham, D. Christiansen, J. Beuth, and A.D. Rollett, Proceedings of Solid Freeform Fabrication Symposium (2015), pp. 626-635.

41. M. Mahesh, B. Lane, A. Donmez, S. Feng, S. Moylan, and R. Fesperman, NISTIR 8036-Measurement Science Needs for Real-time Control of Additive Manufacturing Powder Bed Fusion Processes (SAE International, 2015).

42. Concept Laser's QMmeltpool 3D: In-situ quality assurance with real-time monitoring down to the micron level, vol. 1, no. 2 (Inovar Communications Ltd, 2015), pp. 69-71.

43. S.S. Babu, L. Love, R. Dehoff, W. Peter, T.R. Watkins, and S. Pannala, MRS Bull. 40, 1154 (2015).

44. W. King, A.T. Anderson, R.M. Ferencz, N.E. Hodge, C. Kamath, and S.A. Khairallah, Mater. Sci. Technol. 31, 957 (2015).

45. A.A. Salem, J.B. Shaffer, D.P. Satko, S. Semiatin, and S.R. Kalidindi, Integr. Mater. Manuf. Innov. 3, 24 (2014).

46. G.A. Sargent, K.T. Kinsel, A.L. Pilchak, A.A. Salem, and S.L. Semiatin, Metall. Mater. Trans. A 43, 3570 (2012).

47. J. Slotwinski and S. Moylan, NISTIR 8005-Applicability of Existing Materials Testing Standards for Additive Manufacturing Materials (2014)

48. J. Slotwinski, A. Cooke, and S. Moylan, NISTIR 7847-Mechanical Properties Testing for Metal Parts Made via Additive Manufacturing: A Review of the State of the Art of Mechanical Property Testing (2012).

49. ISO/ASTM Standard 52915, Standard Specification for Additive Manufacturing File Format (AMF) Version 1.1 1, in ASTM Book of Standards, vol. 2013 (ASTM International, West Conshohocken, 2013), pp. 1-15.

50. ISO/ASTM Standard 52921, ASTM Book of Standards (West Conshohocken: ASTM International, 2013).

51. Technology Exchange on Coordination of U.S. Standard Development for Additive Manufacturing. [Online]. http:// www.cimp-3d.org/event/2015/oct/7-8/standards-coordination. Accessed 15 Sep 2015.

52. N. Hrabe and T. Quinn, Mater. Sci. Eng. A 573, 271 (2013).

53. D. Greitemeier and C. Dalle, Appl. Mech. Mater. 807, 169 (2015).

54. ASTM Standard F3122, ASTM Book of Standards (West Conshohocken: ASTM International, 2014).

55. ASTM WK49229, New Guide for Anisotropy Effects in Mechanical Properties of AM Parts (West Conshohocken: ASTM International, 2015).

56. ASTM WK47031, Standard Guide for Nondestructive Testing of Metal Additively Manufactured Parts Used in Aerospace Applications (West Conshohocken: ASTM International, 2015).

57. M. Seifi, I. Ghamarian, P. Samimi, P.C. Collins, and J.J. Lewandowski, Ti-2015: The 13th World Conference on Titanium (Wiley, 2016).

58. M. Seifi, A. Salem, D. Satko, and J.J. Lewandowski, Case Western Reserve University, Cleveland, $\mathrm{OH}$, unpublished research.

59. M. Seifi, A. Salem, D. Satko, U. Ackelid, and J.J. Lewandowski, Case Western Reserve University, Cleveland, $\mathrm{OH}$, unpublished research, 2016.

60. P. Li, D.H. Warner, A. Fatemi, and N. Phan, Int. J. Fatigue (2015).

61. H.K. Rafi, N.V. Karthik, H. Gong, T.L. Starr, and B.E. Stucker, J. Mater. Eng. Perform. 22, 3872 (2013). 
62. Y.T. Wu, M.P. Enright, and H.R. Millwater, AIAA J. 40, 937 (2002).

63. P.M. Singh, N.J.H. Holroyd, and J.J.Lewandowski, Parkins Symposium on Fundamental Aspects of SCC (1992), pp. 567-583.

64. J.J. Lewandowski, P.M. Singh, and N.J.H. Holroyd, Jaffee Symposium on Clean Materials Technology (1992), pp. 2939.

65. C. Ward and J.A. Warren, NISTIR 8038-Materials Genome Initiative: Materials Data (2015).

66. Materials Genome Initiative National Science and Technology Council Committee on Technology Subcommittee on the Materials Genome Initiative, Executive Office of the President (2014).

67. Materials Genome Initiative for Global Competitiveness (Washington, 2011).

68. Linking transformational materials and processing for an energy-efficient and low-carbon economy: Creating the Vision and Accelerating Realization-Opportunity Analysis for Materials Science and Engineering (The Minerals, Metals \& Materials Society, 2010).

69. Linking Transformational Materials and Processing for an Energy Efficient and Low-Carbon Economy: Creating the Vision and Accelerating Realization- Innovation Impact Report (The Minerals, Metals \& Materials Society, 2011).

70. The Minerals Metals \& Materials Society (TMS), Modeling Across Scales: A Roadmapping Study for Connecting Mate- rials Models and Simulations Across Length and Time Scales (The Minerals, Metals \& Materials Society, 2015).

71. S.R. Kalidindi and M. De Graef, Annu. Rev. Mater. Res. 45, 171 (2015).

72. K. Rajan, Annu. Rev. Mater. Res. 45, 153 (2015).

73. W. Marsden, D. Cebon, S. Warde, and G. Design, AIAA SciTech, (January 2015), pp. 1-9.

74. Linking transformational materials and processing for an energy-efficient and low-carbon economy: Creating the Vision and Accelerating Realization-Vision Report of the Energy Materials Blue Ribbon Panel (The Minerals, Metals \& Materials Society, 2010).

75. D. Pal, N. Patil, M. Nikoukar, K. Zeng, K. Kutty, and B. Stucker, Proceedings Solid Freeform Fabrication Symposium (2013).

76. C.A. Brice, Proceedings of the 1st World Congress on Integrated Computational Materials Engineering, ICME (2011), pp. 241-246.

77. D.H. Abbott, SAE Specification Summit (2015)

78. AMS4999A, SAE Aerospace (SAE International, Warrendale, 2011), pp. 1-11.

79. J.E. Duven, Advisory Circular 25.621-1: Casting Factors (2014), pp. 1-11.

80. NIST, Qualification for Additive Manufacturing Materials, Processes, and Parts (2014) [Online]. http://www.nist.gov/el/ isd/sbm/qammpp.cfm. 